\title{
Carbapenem-resistant Enterobacteriaceae: biology, epidemiology, and management
}

\author{
Elizabeth Temkin, ${ }^{1}$ Amos Adler, ${ }^{1,2}$ Anat Lerner, ${ }^{1}$ and Yehuda Carmeli ${ }^{1,2}$ \\ ${ }^{1}$ Division of Epidemiology and Preventive Medicine, Tel Aviv Sourasky Medical Center, Israel. ${ }^{2}$ Sackler Faculty of Medicine, \\ Tel Aviv University, Israel \\ Address for correspondence: Yehuda Carmeli, M.D., M.P.H., Division of Epidemiology and Preventive Medicine, Tel Aviv \\ Sourasky Medical Center, Weizmann St. 6, Tel Aviv 64239, Israel. yehudac@tlvmc.gov.il
}

Introduced in the 1980s, carbapenem antibiotics have served as the last line of defense against multidrug-resistant Gram-negative organisms. Over the last decade, carbapenem-resistant Enterobacteriaceae (CRE) have emerged as a significant public health threat. This review summarizes the molecular genetics, natural history, and epidemiology of CRE and discusses approaches to prevention and treatment.

Keywords: carbapenem-resistant Enterobacteriaceae; antimicrobial resistance; carbapenemases; molecular genetics; infection control; treatment

\section{Background and history}

Carbapenems, the most broad-spectrum betalactam antibiotics active against Gram-negative organisms, are very slowly hydrolyzed by most betalactamases. Because of this, agents from this class have been used successfully and have served as the last line of defense against multidrug-resistant Gram-negative organisms since their introduction in the early 1980s. Carbapenemases-betalactamases that hydrolyze carbapenems efficiently, such as the serine carbapenemase SME and the metallo-beta-lactamase IMP-were detected in Enterobacteriaceae in the 1980s. ${ }^{1-3}$ However, with the exception of limited spread of IMP-producing bacteria in Japan, ${ }^{4,5}$ most reports remained anecdotal, with no significant spread for over 20 years.

The serine carbapenemases include the group A enzyme families SME, GES, IMI, NMC, KPC (of which only KPC has gained epidemiologic success and will be discussed here), and the class D OXA enzymes (of which OXA-48 has gained success among Enterobacteriaceae and will be discussed). Two metallo-carbapenemases, VIM and NDM, have become important threatening pathogens. Other metallo-carbapenemases, including IMP, SPM, GIM, and SIM, are spreading locally and will not be addressed here.
Widespread carbapenemase production in the Enterobacteriaceae was unknown until the early 2000s; almost all carbapenemase-resistant isolates reported were sporadic cases of hyperproduction of the beta-lactamase AmpC or of extended spectrum beta-lactamase, combined with porin loss. In 2001, the first report of carbapenem-resistant Klebsiella pneumoniae carrying a new carbapenemase, KPC, was published. ${ }^{6}$ This strain was previously isolated in a North Carolina intensive care unit (ICU) in 1996, but went unnoticed at the time. However, the strain was stored at the Centers for Disease Control and Prevention (CDC) as part of an ICU pathogen collection, and then investigated several years after its first isolation. Through 2004 only a few isolates of KPC-producing strains from various localities extending from Baltimore to New York City were reported in the literature. Retrospectively, it is clear that large outbreaks, some reported to the CDC, occurred in multiple hospitals in the northeastern United States and Arizona. Indeed, in 2004 investigators from England's Health Protection Agency, together with colleagues from Tisch Hospital in New York City, reported on a KPC-producing K. pneumoniae outbreak in 2000-2001 that affected 24 patients and had a case fatality rate of $33 \%{ }^{7}$ The medical community began to pay attention 
to the problem only after researchers from Brooklyn, N.Y. reported, in several publications, that 62 $(24 \%)$ of $257 \mathrm{~K}$. pneumoniae isolates in their center were KPC producers, ${ }^{8}$ and, later, that 96 isolates collected from 10 Brooklyn hospitals during 2003-2004 were KPC producers. ${ }^{9}$ The magnitude of the problem became clear when the National Healthcare Safety Network reported that among the nosocomial pathogens reported during 20062007 from 463 hospitals throughout the U.S., 10$11 \%$ of all K. pneumoniae isolates causing central line-associated bloodstream infections or urinary tract infections were resistant to carbapenems. ${ }^{10}$ Thus, between 1996 and 2006, KPC-producing K. pneumoniae had spread endemically throughout the U.S. as an important nosocomial pathogen. In parallel, from 2005 onward, reports of the spread of KPCproducing strains appeared from multiple countries and various parts of the world, with notable nationwide outbreaks in Israel, ${ }^{11,12}$ Greece, ${ }^{13,14}$ and Italy. ${ }^{15}$

The VIM family of enzymes was first reported in Italy in 1997 in Pseudomonas aeruginosa isolates. The first VIM-producing Enterobacteriaceae were isolated in 2001 in Greece, ${ }^{16}$ strains that gained endemicity in Greece and eventually led to $50 \%$ carbapenem resistance among $K$. pneumoniae isolates from Greek ICUs in 2006. ${ }^{17}$ VIM-producing Enterobacteriaceae have also spread locally in Italy ${ }^{18}$ and, to a limited extent, in Spain. ${ }^{19}$

The spread of KPC and VIM was followed and paralleled by the spread of NDM, primarily in the Indian subcontinent and from there elsewhere, and by the spread of OXA- 48 around the eastern and southern parts of the Mediterranean basin. The spread of these four enzymes resulted in high endemicity of carbapenem-resistant Enterobacteriaceae (CRE) in multiple regions and threatening to spread elsewhere.

\section{Molecular genetics of CRE}

\section{The epidemic of KPC}

$\mathrm{KPC}$ is a serine class-A type enzyme that exhibits activity against all types of $\beta$-lactam agents. ${ }^{20,21}$ The primary mode of KPC spread is via the clonal dissemination of K. pneumoniae. The dominant KPCproducing clones are the sequence type (ST) 258 clone ${ }^{22}$ and its related single locus variant (SLV) ST-512, ${ }^{23,24}$ and ST-11, a more distant SLV of ST$258 .^{22,25-27}$ The basis for the success of the ST-258 clone remains to be explained. A comparison be- tween KPC-producing strains belonging to the ST258 epidemic clone (from Israel and the U.S.) and 21 strains belonging to other, infrequently occurring clones (from Israel and the U.S.) identified a set of supposedly unique genes. ${ }^{28}$ In a follow-up large multinational study (Israel, U.S., Colombia, Greece, and Italy) using other strains, the uniqueness of some of the genes was not confirmed. ${ }^{29}$

In contrast with the dominant monoclonal spread of KPC-producing K. pneumoniae, the initial reports of KPC-producing E. coli and Enterobacter species showed mainly polyclonal spread. ${ }^{30,31}$ This raises the particular concern that the transfer of the KPC gene $\left(b l a_{\mathrm{KPC}}\right)$ into global epidemic clones, such as the reported ST-131 E. coli strain, ${ }^{32-34}$ will lead to wide dissemination of KPC in the population at large. Thus far, however, community-acquired infections have not been reported. The KPC gene has also been identified in many other bacterial species, including species that are rarely detected in humans, ${ }^{35}$ and in non-Enterobacteriaceae such as $P$. aeruginosa. ${ }^{36}$

\section{Alleles, promoters, and mobile genetic elements}

Although more than 14 different $b l a_{\mathrm{KPC}}$ allele sequences have been submitted to the National Center for Biotechnology Information (NCBI) database, the majority of clinical reports have been the $b a_{\mathrm{KPC}-2}$ or $b l a_{\mathrm{KPC}-3}$ alleles. ${ }^{12}$ The KPC gene is located inside the $\sim 10 \mathrm{~kb}$ Tn3-related transposon Tn4401, for which there are five isoforms that differ in the promoter areas upstream of $b l a_{\mathrm{KPC}} \cdot{ }^{37}$ Factors found to be related to the carbapenem minimum inhibitory concentration (MIC) in clinical isolates include the copy number and the presence of a permeability defect, such as the loss of OmpK36 in K. pneumoniae. ${ }^{38}$ The bla $a_{\mathrm{KPC}}$-containing Tn4401 transposon has a high efficiency of mobilization and no target size specificity, which together provide the capacity to mobilize to a wide variety of genetic environments. ${ }^{39}$ Indeed, Tn 4401 has been identified in a wide variety of plasmids from different incompatibility (Inc) groups, such as FII, L/M, and N. ${ }^{22,40}$

The data regarding the association between different types of $b l a_{\mathrm{KPC}}$-harboring plasmids and different species and geographic locations are complex. In Israel, several studies have identified a common IncFII type plasmid (designated pKpQIL) in the epidemic ST-258 K. pneumoniae clone, ${ }^{41}$ whereas 
IncN type plasmids were common in other species and K. pneumoniae clones. ${ }^{22,35}$ pKpQIL was identified in KPC-producing K. pneumoniae strains from New York and New Jersey, predating the Israeli outbreak; ${ }^{42}$ this plasmid has also been reported from various countries including Poland, Italy, and the United States. ${ }^{25,43}$ In some areas, a wide variety of plasmids have been found in all clones, including ST-258. ${ }^{22,25,40}$ Thus, while clonal expansion is the primary mechanism of spread of $b l a_{\mathrm{KPC}}$, complex modes of horizontal gene transfer also play an important role in the spread of KPC. ${ }^{44,45}$

\section{OXA-48 and related enzymes}

The OXA-48 enzyme is a serine class $\mathrm{D}$ type $\beta$-lactamase that exhibits high activity against penicillins, minimally hydrolyses carbapenems, and shows weak activity against expanded-spectrum cephalosporins. ${ }^{46}$ However, because OXA-48producing strains often also carry extendedspectrum beta-lactamase (ESBL) enzymes, they are resistant to expanded-spectrum cephalosporins. Unlike other OXA-type carbapenemases that are common in, for example, Acinetobacter baumannii and other non-fermenting Gram-negative rods, OXA-48 and its related variants (OXA-162, -163 , $-181,-199,-204,-232,-244$, and -245) are present in Enterobacteriaceae. ${ }^{4-53}$ The OXA-48 enzymes have mixed modes of spread: plasmid, transposon, and clonal, the latter being characterized by polyclonal dissemination on a global scale, as well as local clonal outbreaks. Some of the dominant OXA-48 producing K. pneumoniae clones, such as ST- $11^{52,54,55}$ and ST-147, ${ }^{54,56}$ are also frequently reported as ESBLproducing clones. ${ }^{57}$ As with KPC, OXA- 48 was identified in the pandemic ST-131 E. coliclone, although this is a single case report. ${ }^{58}$

The OXA-48 gene $\left(b l a_{\text {OXA-48 }}\right)$, carried by Tn1999-a composite transposon made of two copies of the insertion sequence IS1999, has several variants that may differ in their mobilization efficiency. ${ }^{59,60} \mathrm{Tn} 1999$ is almost universally located inside an IncL/M-type 63-kb plasmid, designated pOXA-48a, ${ }^{61}$ which has been shown to exhibit extremely efficient self-conjugation potential, both intra- and inter-species, ${ }^{62}$ and is linked to many of the plasmids outbreaks. OXA-48-producing Enterobacteriaceae (and hence the $b l a_{\text {OXA-48 }}$ gene) originated in the Middle East and North Africa and spread to many other countries in Europe and elsewhere. ${ }^{52,63,64}$ In contrast, $b l a_{\mathrm{OXA}-181}$ (and its closely related allele $b l a_{\text {OXA-232 }}$ ) likely originated from the environmental species Shewanella xiamenensis, ${ }^{65}$ and are located on a different transposon, Tn2013, with the insertion sequence ISEcp1 at one end. ${ }^{51,53} \operatorname{Tn} 2013$ is found on relatively small ColE-type non-conjugative plasmids. ${ }^{51,53}$ OXA181-producing Enterobacteriaceae show different epidemiology from OXA-48-producing Enterobacteriaceae, and they have been identified almost exclusively among patients originating from India. ${ }^{66}$

\section{Metallo-beta lactamases: NDM and VIM}

\section{NDM-1}

The epidemic of New Delhi metallo-beta-lactamase (NDM) is primarily the dissemination of bla $a_{\mathrm{NDM}}$ spreading between plasmids, clones, and strains; $b l a_{\mathrm{NDM}}$ is found on many different types of plasmids and can be chromosomal as well. ${ }^{67,68}$ Not uncommonly, more than one NDM-producing species can be isolated in a single patient, suggesting transmission via mobile genetic elements. ${ }^{69}$ The molecular epidemiology of NDM in the most commonly isolated species, E. coli and K. pneumoniae, is also complex. In some cases NDM has been related to clonal spread, whereas in other locations the clonal structure is diverse. ${ }^{67,68,70} \mathrm{NDM}$-producing E. coliST-101 has been commonly reported; ${ }^{67,70}$ and $b l a_{\mathrm{NDM}}$ has been identified in the epidemic clone ST- $131 .{ }^{67}$ As of July 2014, there were 12 known alleles of bla $a_{\mathrm{NDM}}$ (deposited at http://www.lahey.org/Studies/); most were identified in Enterobacteriaceae, but some also in Acinetobacter species. ${ }^{71-77}$ The alleles exhibit more than $99.4 \%$ similarity and have similar or even higher catalytic activity compared to $b l a_{\mathrm{NDM}-1}{ }^{71}$

\section{VIM}

VIM (Verona integron-encoded metallo-betalactamase) is an important MBL that is spread in non-fermenter strains, as well as among Enterobacteriaceae. ${ }^{78}$ As of July 2014, 41 different bla $a_{\mathrm{VIM}}$ allelic variants have been identified (deposited at http://www.lahey.org/Studies/). The bla $a_{\mathrm{VIM}-2}$ group of genes was detected mainly in non-fermenting Gram-negative bacteria, such as Pseudomonas spp. and Acinetobacter spp., while the $b l a_{\mathrm{VIM}-1}$ group was detected mostly among Enterobacteriaceae. ${ }^{78-80}$

The $b l a_{\mathrm{VIM}}$ genes are often located in class 1 integrons as gene cassettes that reside on plasmids 
with different replicon types, for example, IncN, IncA/C, and IncI. ${ }^{78,79,81-83}$ In K. pneumonia, many of the VIM-1/4 genes are carried on plasmids with Inc group N, whereas those genes carried by $E$. coli are often IncFI/II. ${ }^{84}$ Isolates of K. pneumoniae carrying both $b l a_{\mathrm{VIM}-1}$ and $b l a_{\mathrm{KPC}-2}$ were reported initially from Greece and, later, from other countries including Italy, Germany, and Colombia. ${ }^{85-89}$

VIM-producing K. pneumoniae isolates from the SMART surveillance program were typed and $63 \%$ were found to belong to ST-147. ${ }^{90}$ Clonal spread of the VIM-carrying ST-147 strains with IncF and IncA/C plasmids was shown to occur within and between hospitals, and even between countries (Greece, Italy, and Scandinavia). ${ }^{90}$ In a report from the Czech Republic, 5 of 6 VIM-producing K. pneumoniae isolates belonged to ST-11. ${ }^{91}$

\section{Diagnosis of CRE}

Accurate and timely diagnosis of CRE is of great importance for determining appropriate treatment and infection control measures. Tests to detect CRE can be divided into phenotypic and genotypic tests. Phenotypic tests can be further divided into those that are directed at detection of elevated MIC to certain carbapenems (such as MIC testing, growth on selective carbapenem containing media) and those that are directed at detection of hydrolysis of carbapenem either directly (cell-free extract hydrolysis assay) or indirectly (the modified Hodge test, the Carba NP test). MIC-based methods have limited sensitivity and specificity. On the one hand, carbapenemase-producing strains may have low MICs; on the other hand, strains with combinations of either ESBL or AmpC and loss of a porin may have high MICs to carbapenems. Hydrolysis tests are more specific, but they are labor intensive and more difficult to perform, and can be applied to isolates but not directly to specimens. Therefore, MIC-based methods using a low cutoff are often used as a first screen that is supplemented with the more specific hydrolysis tests. To treat CRE that are extremely drug resistant, clinicians need maximum information from diagnostic tests; the exact accurate MIC for various antibiotics is required, as well as which carbapenemase is involved. Determining the carbapenemase involved is also important in order to understand the local epidemiology and to design infection control measures. Genotypic tests, which involve amplification and detection of specific bla genes using polymerase chain reaction (PCR), are highly specific and sensitive for detecting specific genes. $^{92}$

In settings where PCR testing is not available, one may rely on imputing the carbapenemase family on the basis of phenotypic testing with and without specific inhibitors, such as EDTA and boronic acid; however, these tests have limited value. Commercial genotypic tests, including rapid ones, are available. The main limitation of PCR tests (beyond their cost) is that a specific gene test may not be sensitive enough to detect all possible carbapenemases.

For detection of CRE carriage in asymptomatic patients, rectal swabs, or stool samples should be used. These specimens are challenging both for phenotypic and genotypic testing. Chromogenic media have been developed and various brands differ in their sensitivity and specificity. As with any diagnostic test, the accuracy of the result is determined by the test characteristics (sensitivity and specificity) and by the prevalence of the condition (pre-test probability). In our opinion, there is no single testing strategy that fits all, and the strategy should be decided on the basis of local epidemiology, targets, and laboratory expertise and equipment. In most settings, the combination of phenotypic and genotypic testing will result in the best performance and most rapid result.

\section{Geography of CRE}

The worldwide presence of CRE has been reviewed in several comprehensive articles. ${ }^{93-95}$ The accuracy of data about CRE depends on countries' capacities for surveillance, laboratory identification, and reporting; it is likely that the available data underestimate the true global prevalence of CRE. MunozPrice et al. have published a helpful world map that classifies countries according to the predominant carbapenemase (KPC or others) and whether CRE is endemic, scattered, or unreported. ${ }^{93}$ Countries with endemic KPC are China, Israel, Greece, Italy, Poland, Colombia, Argentina, Brazil, and some states in the United States. Other carbapenemases are endemic in India (NDM) and Turkey (OXA-48).

As of February 2014, cases of KPC-producing Enterobacteriaceae have been reported in all U.S. states except Maine, Idaho, and Alaska. The NDM carbapenemase has been reported in 15 states; VIM in California, Kentucky, and Washington; and IMP in California and Washington. ${ }^{96}$ The National 
Healthcare Safety Network (NHSN) tracks antibiotic resistance among organisms causing deviceassociated infections acquired in acute care hospitals. (Because hospitals' participation is voluntary, the findings may not be generalizable to the country as a whole and do not address regional variation within the United States.) In 2009-2010, carbapenem resistance was present in $12.8 \%$ of Klebsiella isolates responsible for central line-associated bloodstream infections (CLABSIs). ${ }^{97}$ CRE infections are relatively uncommon in the United States. In the first half of 2012, among nearly 4000 hospitals participating in the NHSN, $4 \%$ of short-stay acute care hospitals and $18 \%$ of long-term acute care hospitals (LTACHs) reported at least one patient with either a catheter-associated urinary tract infection or a CLABSI caused by CRE. ${ }^{93,98}$

In Europe, the European Antimicrobial Resistance Surveillance Network (EARS-Net) monitors resistance among pathogens isolated from blood or cerebrospinal fluid. In 2012, among the 23 countries that contributed at least 100 isolates (samples that may not be representative of the whole country), the proportion of $K$. pneumoniae isolates that were carbapenem resistant was $<1 \%$ in 18 countries, $1-7 \%$ in 3 countries, $29 \%$ in Italy, and $61 \%$ in Greece. ${ }^{99}$

\section{Natural history of CRE}

When considering CRE, it is various enterobacterial species and clones that carry mechanisms of resistance, and spread is via the fecal-oral route. Thus, acquisition of CRE begins with ingestion; following ingestion, CRE colonize the digestive tract of some patients. Whether colonization occurs depends on factors such as the inoculum ingested, characteristics of the specific clone, and patient characteristics that resist colonization, such as gastric acidity and the composition of the gut flora. ${ }^{100}$ Antibiotics disrupt the normal gut flora, eradicate susceptible bacteria, and allow the overgrowth of resistant bacteria. Indeed, several studies have identified recent antibiotic use as a risk factor for CRE colonization. ${ }^{101-103}$

The source of ingested CRE can vary. Currently, KPC-producing strains spread primarily in healthcare settings from hospitalized patients who are carriers. The mode of transmission is via contaminated hands of healthcare workers or contaminated fomites. Preventing transmission and spread of KPC, therefore, should be directed at improving healthcare practices (such as hand hygiene) and patient isolation. The NDM-producing strains spread primarily in the Indian subcontinent and most transmission occurs in the community, possibly by contaminated potable water owing to poor sanitation systems. ${ }^{104}$ We speculate that for the OXA-48-producing strains, community spread in southern and eastern Mediterranean countries may be explained by poor food hygiene. Thus, in these settings prevention should be directed at improving sanitation and hygiene.

Duration of carriage likely differs among species and clones, as some enterobacteria are more adapted to the human gut environment than others. Estimating the duration of CRE colonization is sometimes difficult because persistent carriers may have intermittent detectable levels of CRE in their stool. This creates several problems. For example, does a negative test indicate no carriage or is it a false negative owing to the concentration of CRE in the sample below the level of detection? (The level of CRE detection from rectal swabs on agar plates was found to range from $6.5 \times 10^{1}$ to $8.3 \times$ $10^{6} \mathrm{CFU} / \mathrm{mL}$, depending on bacterial strain and laboratory methods. ${ }^{105}$ ) Another problem is that serial tests cannot distinguish between persistent carriage and clearance followed by re-acquisition. Feldman et al. screened KPC-producing K. pneumoniae carriers serially after hospital discharge; ${ }^{106}$ only if two consecutive tests (both culture and PCR) were negative was the patient considered to have cleared carriage. At 1 to 30 days after the initial positive test, $74 \%$ of carriers were still positive; $54 \%$ remained positive after $30-60$ days; $46 \%$ after 60 90 days; $28 \%$ after 6 months to 1 year; and $14 \%$ after 1 year. Heterogeneous studies using different time frames to define persistence have identified risk factors for persistent carriage; these include hospitalization or long-term care stay, ${ }^{106-108}$ antibiotic use, ${ }^{101,107}$ and poor functional status and multiple co-morbidities. ${ }^{106}$

In a proportion of carriers, CRE will migrate from the digestive tract to another site, such as the bloodstream, urinary tract, or a wound, resulting in CRE infection. The proportion of carriers in which this occurs is determined by a variety of factors, including their immune status, the presence of invasive devices or being subjected to invasive procedures, and antibiotic exposure. Two studies 
among hospitalized patients estimated that between $7.6 \%$ and $9.1 \%$ of carriers will develop CRE infection. ${ }^{109,110}$ However, in certain populations, such as bone marrow transplant recipients, this proportion may be much higher, reaching $75 \%$.

\section{Clinical manifestations of CRE}

CRE, like other enterobacteria, may cause a variety of infections. Most commonly, infections caused by CRE include urinary tract, intra-abdominal, bacteremia, pneumonia (ventilator associated or not), and skin and soft tissue (including surgical site). Clinical symptoms of infections caused by CRE are identical to those caused by susceptible strains. A methodological concern in studies that compare the mortality and morbidity of patients infected with resistant bacteria to other patients is that the former group tends to have additional risk factors, such as more severe underlying illness and longer hospitalization, which make them more likely to have worse outcomes. Most welldesigned studies that controlled for these potential confounders ${ }^{111-115}$ found 3-6 times higher mortality among CRE-infected patients than those either infected with carbapenem-susceptible Enterobacteriaceae or without CRE infection, although another study found no difference. ${ }^{116}$

The higher mortality associated with CRE infections is likely not because the pathogen itself is more virulent but because adequate treatment is delayed or unavailable, and because available treatment options are less efficacious compared with agents used to treat susceptible organisms. ${ }^{17}$ In a study by Ben-David et al., in which the risk of death was nearly four times higher for patients with carbapenem-resistant K. pneumoniae (CRKP) bacteremia than for patients with carbapenemsusceptible K. pneumoniae bacteremia, only $12 \%$ of patients in the former group received appropriate empiric therapy compared with $79 \%$ in the latter group. ${ }^{115}$ Even timely, appropriate treatment (i.e., antibiotics with in vitro activity against CRE) does not necessarily improve outcomes. In two studies comparing patients with CRKP infection who died during their hospital stay to those who survived, receiving an antibiotic with in vitro activity against CRKP did not improve survival. ${ }^{113,118}$ The high inhospital mortality (over 50\% in both studies) among CRKP-infected patients who receive an active antibiotic may reflect confounding factors such as de- layed treatment and greater severity of underlying illness, compared with patients with carbapenemsusceptible infections.

\section{Epidemiology of CRE in healthcare settings}

In developed countries CRE transmission occurs almost exclusively within healthcare settings. The main route of spread is from patient to patient via contaminated hands of healthcare workers, although transmission has also been traced to contaminated endoscopes ${ }^{119}$ as well as sinks and drain pipes. ${ }^{120}$ Three steps are required for a healthcare worker to spread CRE from patient to patient; the worker must touch a patient colonized or infected with CRE (or their contaminated surroundings), become temporarily contaminated with CRE, and then touch a non-colonized patient while still contaminated (e.g., without changing gloves or washing hands). Colonization pressure is defined as the proportion of patients who are already colonized or infected with a particular pathogen. When colonization pressure is zero, there is no chance that the first step will occur. When colonization pressure is high, it is highly likely that the first step will occur. Thus, the risk of acquiring CRE (or any MDRO (multidrug-resistant organism)) depends not only on characteristics of the individual patient but also on the status of other patients, ${ }^{121}$ as well as on local conditions, for example, availability of isolation rooms, staff-to-patient ratio, and compliance with hand hygiene. A study conducted in two New York hospitals found that the odds of CRE acquisition increased by $15 \%$ per each $1 \%$ increase in colonization pressure. ${ }^{102}$ Other risk factors for hospital-acquired CRE carriage or infection include prolonged hospital stay, ICU stay, antibiotic use, poor functional status, adult diaper use (either as a marker for being severely debilitated or representing the risk for fecal material contamination), and the presence of multiple invasive devices or mechanical ventilation. ${ }^{31,102,103,111}$

Long-term care settings-including LTACHs and post-acute care hospitals $(\mathrm{PACH})$ that treat seriously ill patients, and nursing homes that provide custodial care-play a key role in the spread of CRE. In a study in the Chicago area, 30\% of residents of LTACHs were CRE carriers, compared to $3.3 \%$ of patients in ICUs in general hospitals. ${ }^{122}$ In a study in post-acute care facilities in Israel, 12\% 
of all patients and $26 \%$ of patients in skilled nursing wards were colonized with CRE. ${ }^{101}$ Patients in these high-acuity long-term settings typically have many risk factors for CRE colonization, including advanced age, multiple co-morbidities, use of multiple invasive devices, high exposure to antibiotics, and prolonged hospitalization. ${ }^{122}$ Few studies have been designed to discern whether CRE carriers in LTACHs acquired CRE while at the facility or arrived from general hospitals already colonized. In one LTACH involved in a multi-facility CRE outbreak in Indiana and Illinois, three patients were positive on admission and seven acquired CRE after admission. ${ }^{123}$

In affected regions, CRE are also prevalent in lower-acuity long-term settings such as nursing homes. A point prevalence survey in a West Virginia nursing home found that $9 \%$ of residents were colonized with CRKP. ${ }^{124}$ The high prevalence in nursing homes stems both from resident characteristics that increase the risk of CRE acquisition (advanced age, co-morbidities) and facility characteristics that promote transmission (shared rooms and communal areas, undesirability of restricting activity in settings that serve as residents' homes, and lack of expertise in infection control). ${ }^{124,125}$ Nursing homes, LTACHs, and PACH serve as CRE reservoirs: even when infection control measures in general hospitals have succeeded in stopping transmission, the influx of colonized patients from longterm care means that there is continual colonization pressure. ${ }^{126}$ Several reports have described CRE outbreaks that spanned a web of general hospitals and long-term care settings. ${ }^{123,127,128}$

\section{Epidemiology of community-acquired CRE}

Transmission of CRE outside of healthcare settings has been documented rarely in developed countries ${ }^{129-131}$ but is more common in developing countries. Suspicion of non-nosocomial CRE transmission was first raised after the initial discovery of NDM-1-producing K. pneumoniae in a patient in Sweden who had been hospitalized in New Delhi; ${ }^{132}$ as NDM-1 was detected in more Westerners returning from the Indian subcontinent, it was noted that not all of them had been hospitalized while abroad. ${ }^{133,134}$ In 2010, a study conducted in hospital laboratories in north and south India reported that the majority of the $148 \mathrm{CRE}$ isolates ana- lyzed were community-acquired infections. ${ }^{68}$ Since then, other reports of community-acquired CRE in developing countries ${ }^{135}$ and in Westerners returning from developing countries ${ }^{136}$ have been published.

Community transmission of CRE in developing countries is presumably oral-fecal (i.e., waterborne and foodborne). ${ }^{100}$ The presence of CRE in water was confirmed by Walsh et al., who sampled public tap water and seepage water in New Delhi. ${ }^{104}$ They detected NDM-1-producing species, including Enterobacteriaceae, in both water sources. Similar studies have detected NDM-1-producing K. pneumoniae in river water in Vietnam ${ }^{137}$ and OXA-48-producing Serratia marcescens in puddles in Morocco. ${ }^{138}$ Other research failed to detect resistance genes in bacteria isolated from raw vegetables in India. ${ }^{139}$

\section{Interventions to control and prevent CRE}

Few interventions to control and prevent CRE have been rigorously evaluated in randomized, controlled trials. Rather, most of the evidence for or against a measure comes from either quasiexperimental studies that compare CRE incidence or prevalence before and after the interventions were implemented or descriptive studies that report resolution of an outbreak. These studies have been nicely summarized in two reviews ${ }^{20,140}$ and nearly all report striking success. For example, a national intervention in Israel reduced the incidence of CRKP detected in clinical cultures from 55.5 to 11.7 per 100,000 patient-days. ${ }^{11}$ In an LTACH in Chicago, the prevalence of CRKP carriage fell from $21 \%$ to $0 \% ;{ }^{141}$ in an ICU in a New York hospital, the incidence of CRKP detected in clinical cultures decreased from 9.7 to 3.7 per 1000 patient-days. ${ }^{142}$ As is standard in the field of infection control, nearly all of the intervention studies involve a bundle approach in which multiple measures are implemented simultaneously. Therefore, it is difficult to determine the effect or relative importance of any individual measure ${ }^{140}$ except by using mathematical models. ${ }^{143}$ Table 1 compares guidelines for CRE control issued by the Israeli Ministry of Health, ${ }^{126}$ the U.S. Centers for Disease Control and Prevention, ${ }^{144}$ and the European Society of Clinical Microbiology and Infectious Diseases' (ESCMID) Study Group for Antimicrobial Resistance Surveillance. ${ }^{145}$ 
Table 1. Comparison of guidelines for prevention and control of CRE transmission

\begin{tabular}{|c|c|c|c|}
\hline Intervention & Israel & United States $^{a}$ & $\begin{array}{l}\text { ESCMID Study group for antimicrobial } \\
\text { resistance surveillance }\end{array}$ \\
\hline Hand hygiene & Required & Core measure & Not addressed \\
\hline \multicolumn{4}{|l|}{ Active surveillance: } \\
\hline On admission & $\begin{array}{l}\text { Required for patients } \\
\text { (1) transferred directly from } \\
\text { another healthcare facility, } \\
\text { (2) hospitalized in an ACH or } \\
\text { LTCF in recent months, or } \\
\text { (3) hospitalized since } 2008 \text { in } \\
\text { countries with known } \\
\text { non-KPC-producing } \\
\text { CRE (e.g., India) }\end{array}$ & $\begin{array}{l}\text { Supplemental measure. Possible } \\
\text { candidates for screening: } \\
\text { patients admitted from LTCF } \\
\text { or from high CRE prevalence } \\
\text { areas or from institutions } \\
\text { known to have CRE; patients } \\
\text { admitted to high-risk units } \\
\text { such as ICU }\end{array}$ & $\begin{array}{l}\text { For countries with no or sporadic CRE: goal is } \\
\text { complete eradication of CRE (search and } \\
\text { destroy). Screen patients transferred from } \\
\text { countries or institutions with epidemic or } \\
\text { endemic CRE; preemptive isolation while } \\
\text { waiting for results. } \\
\text { For countries with endemic or ongoing } \\
\text { outbreaks of CRE: goal is maximum } \\
\text { containment of CRE. Screen patients with } \\
\text { previous contact with medical facilities with } \\
\text { known ongoing CRE outbreaks. }\end{array}$ \\
\hline During hospitalization & $\begin{array}{l}\text { Required for patients } \\
\text { epidemiologically linked to a } \\
\text { patient newly diagnosed with }\end{array}$ & $\begin{array}{l}\text { Core measure for patients } \\
\text { epidemiologically linked to a } \\
\text { patient newly diagnosed with }\end{array}$ & $\begin{array}{l}\text { Advised for patients epidemiologically linked } \\
\text { to a patient newly diagnosed with CRE } \\
\text { carriage or infection }\end{array}$ \\
\hline
\end{tabular}

Patient cohorting

Dedicated staffing

Dedicated equipment CRE carriage or infection; optional routine periodic screening in high-risk units CRE carriage or infection; routine periodic screening in high-risk units is optional supplemental measure

Required in $\mathrm{ACH}$. Within the

Core measure for $\mathrm{ACH}$ and cohort, patients with KPC are in separate rooms from patients with other carbapenemases (OXA-48, NDM-1, and VIM) to prevent cross-transmission; not required in LTCF rehabilitation wards (i.e., wards without medically complex or ventilated patients) if prevalence $<3 \%$. Required in $\mathrm{ACH}$; not required in LTCF

Required in ACH and LTCF: medical equipment (e.g., blood pressure cuffs) is not shared among patients with CRE and patients without CRE

Hospitals send daily census of incident and prevalent CRE cases (carriage or infection) to National Center for Infection Control

Not addressed

\section{Core measure for $\mathrm{ACH}$ and \\ LTCH \\ Not addressed \\ Advised \\ Not addressed}
Core measure for ACH; in LTCF use only for patients at high risk of transmitting CRE (i.e., ventilator dependent, require full assistance with activities of daily living, incontinent of stool, have wounds with drainage that are difficult to control)

Recommended that laboratories report positive test for $\mathrm{CRE}$ to health department, particularly in regions with no known CRE prevalence
Supplemental measure when core measures are not successful in decreasing CRE incidence

Advised

For countries with no or sporadic CRE: have action plan in place that includes reporting all cases to public health authorities

For countries with endemic or ongoing outbreaks of CRE: hospitals should send daily census of CRE carriers to public health authorities (national CRE task force)

Not addressed 
Table 1. Continued

\begin{tabular}{|c|c|c|c|}
\hline Intervention & Israel & United States $^{a}$ & $\begin{array}{l}\text { ESCMID Study group for antimicrobial } \\
\text { resistance surveillance }\end{array}$ \\
\hline $\begin{array}{l}\text { Minimize use of invasive } \\
\text { devices }\end{array}$ & Not addressed in context of CRE & Core measure & Not addressed \\
\hline $\begin{array}{l}\text { Selective digestive } \\
\text { decontamination }\end{array}$ & Not addressed & Not addressed & Not advised because of lack of evidence \\
\hline $\begin{array}{r}\text { Antimicrobial } \\
\text { stewardship }\end{array}$ & Not addressed in context of CRE & Core measure & Not addressed \\
\hline
\end{tabular}

${ }^{a}$ Core measures are required. Supplemental measures are to be used if core measures have failed to control CRE. $\mathrm{ACH}$, acute care hospital; LTCF, long-term care facility.

\section{Interventions to prevent transmission of CRE}

\section{Active surveillance}

Asymptomatic gastrointestinal carriers of CRE can be reservoirs for transmission. The purpose of active surveillance (screening) is to identify carriers so that the infection control measures discussed below can be implemented to prevent carriers from transmitting CRE to susceptible patients. The alternative to active surveillance-identifying carriers only when a culture performed as part of clinical care is positive for $\mathrm{CRE}$ - misses a large proportion of carriers; in an Israeli study, for example, 52\% of patients with CRE were identified by screening and $48 \%$ by clinical culture. ${ }^{146}$ Active surveillance is generally performed by rectal swab, although stool specimens, perirectal swabs, or cultures of wounds or urine (from catheterized patients) have also been used. ${ }^{144}$ Surveillance specimens may be processed using molecular (PCR) or culture-based methods. Compared to culture-based methods, the advantages of molecular methods are rapid turn-around time (particularly important when results trigger the isolation of potential transmitters) and higher sensitivity. Disadvantages are that they test for typically only a single mechanism of resistance and thus may miss others, and they do not identify species or antimicrobial susceptibilities and so cannot be used to guide empiric therapy if clinical infection develops. ${ }^{147,148}$

An active CRE surveillance program must specify whom and when to screen. Different recommendations regarding screening are listed in Table 1. Patients at risk for CRE carriage may be screened on admission to a facility (hospital). Although Israeli and U.S. guidelines consider a patient's region or country of origin in assessing risk, the European Centre for Disease Prevention and Control rejects classi- fying countries as low- or high-risk and screening only patients from the latter group, as the true CRE prevalence of any country is unknown. ${ }^{149}$ Ideally, patients screened on admission should be placed on preemptive contact precautions in a single room until the test results are reported. ${ }^{150}$

Screening during the course of hospitalization is recommended for patients who are epidemiologically linked to a patient with newly detected CRE carriage or infection. If the index case is detected in a high-risk unit, such as an intensive care or transplant unit, all other patients in the unit should undergo screening. In lower-risk units, the infection control staff should determine which patients are epidemiologically linked to the index case depending on proximity, duration of contact, and shared caregivers. ${ }^{126}$ Institutions may also choose to perform ongoing screening in units with a high incidence or prevalence of CRE. In a study conducted in one New York hospital, all ICU patients were screened for CRE on admission and then weekly. Of the 79 patients (out of over 11,000 screened) in whom CRE carriage was detected, $46 \%$ tested positive on admission and $54 \%$ were identified on weekly screening. ${ }^{151}$ It is important to stress that active surveillance is not in and of itself an effective infection control measure. For example, one hospital that implemented CRE screening but not subsequent measures to limit the transmission potential of carriers detected by screening was unsuccessful in reducing CRE incidence. ${ }^{140}$

\section{Cohorting and dedicated staffing}

Cohorting refers to housing patients with CRE carriage/infection together in an area physically separated from non-carriers in order to minimize opportunities for transmission from carriers to noncarriers. In dedicated staffing (also known as staff cohorting), on any given shift, nurses who care for patients in the CRE cohort do not also care for CRE 
non-carriers, thus preventing nurses from serving as vectors of transmission. ${ }^{11}$ In one hospital that instituted CRE control measures in a stepwise fashion, simply isolating CRE carriers in single rooms was unsuccessful in slowing the outbreak; cohorting and dedicated staffing were the actions that led to the steepest decline in CRE incidence. ${ }^{152}$ The burdens imposed by dedicated staffing are not negligible. Hospital-wide staffing is strained as nurses assigned to the CRE cohort are unavailable to fill in elsewhere; morale may wane among nurses in the cohort who are isolated from colleagues and prevention fatigue may lead to lapses in infection control technique. ${ }^{153}$

\section{Contact precautions}

Contact precautions-recommended for control of all MDROs, not just CRE—aim to limit the spread of organisms transmitted by direct or indirect contact with patients or their environment. ${ }^{154}$ The three components of contact precautions are hand hygiene before donning a gown and gloves, donning a gown and gloves before entering the patient's room, and removing gown and gloves and performing hand hygiene before leaving the patient's room. ${ }^{144}$ The impact of contact precautions is limited by healthcare workers' compliance. During a CRE outbreak in a Puerto Rican hospital, staff performed adequate hand hygiene in $48 \%$ of encounters with patients on contact precautions and wore gowns and gloves in $62 \%$ of such encounters. ${ }^{155}$ One U.S. hospital confronting a CRE outbreak achieved nearly total compliance by assigning to each cohort area a healthcare worker whose sole duty was to enforce hand hygiene and contact precautions. ${ }^{153}$

\section{Environmental cleaning}

CRE carriers shed the organism into their surrounding environment. Lerner et al. cultured the bed sheets, bedside tables, and infusion pumps of 34 CRE carriers and detected CRE on at least one of these surfaces in the vicinity of $88 \%$ of the carriers. ${ }^{156}$ Although the exact role of environmental contamination in CRE transmission remains unknown, increasing the frequency and extent of cleaning has been a component of most infection control bundles to reduce CRE. In outbreak situations, it may be necessary to shut down affected units in order to perform thorough cleaning. ${ }^{142,157} \mathrm{Ob}$ servation of environmental cleaning practices may expose previously unidentified gaps that can be corrected. During a CRE outbreak in a U.S. LTACH, observers discovered that cleaning personnel never cleaned surfaces close to patients, such as bed rails and intravenous pumps. It was explained that as part of a policy to prevent patient injury, nurses had been assigned to clean these surfaces; interviews with nurses, however, revealed that they did not do so. The problem was solved by transferring all responsibility for cleaning to the cleaning staff. ${ }^{141}$

\section{Chlorhexidine baths}

Chlorhexidine gluconate is a broad-spectrum antiseptic. The rationale for chlorhexidine baths is to reduce the microbial burden on patients' skin to prevent secondary contamination of the environment. ${ }^{158}$ In a multicenter, cluster-randomized, crossover trial comparing daily patient baths with $2 \%$ chlorhexidine wipes or non-antimicrobial washcloths, chlorhexidine reduced the acquisition of methicillin-resistant $S$. aureus or vancomycinresistant Enterococcus by $23 \% .{ }^{158}$ No similar trial has been conducted for CRE, but two studies ${ }^{141,159}$ included 2\% chlorhexidine baths for all patients in the bundle of interventions to control a CRE outbreak. The CDC recommends chlorhexidine baths as a supplemental strategy when core measures have failed to reduce CRE incidence. ${ }^{144}$ Notably, isolates belonging to the dominant clone of KPC-producing K. pneumoniae, ST-258, were found to have reduced susceptibility to chlorhexidine, which may in part explain that clone's success in hospital settings. ${ }^{160}$

\section{Interventions to prevent CRE carriage from progressing to infection}

\section{Selective digestive decontamination}

Selective digestive decontamination (SDD) involves administering oral non-absorbable antibiotics with the immediate aim of eradicating gastrointestinal carriage of MDROs. The ultimate aims of SDD are to prevent MDRO carriage from progressing to infections, such as bacteremia and pneumonia, and to prevent MDRO transmission to other patients. Three studies with a control group have examined SDD using gentamicin and/or colistin to eradicate CRKP carriage. Two studies ${ }^{161,162}$ found a significant reduction in short-term CRKP carriage among patients treated with SDD compared to controls, while the third study ${ }^{163}$ found no difference. Lubbert's study, ${ }^{163}$ the only one that measured secondary antibiotic resistance, also found that resistance to colistin and gentamicin increased in the 
SDD group. In Saidel-Odes' study, ${ }^{161}$ the difference in CRKP carriage between the SDD group and the control group was no longer statistically significant after 6 weeks. Conclusive data on SDD's effectiveness for preventing infections and transmission, and its ecological safety regarding antibiotic resistance, are lacking. ${ }^{164,165}$ Therefore, SDD for CRE carriage should be reserved for special cases such as a carrier awaiting high-risk chemotherapy or transplant. When used, resistance to the agents used for SDD should be anticipated and monitored to prevent the spread of even more resistant CRE strains.

\section{Limiting the use of invasive devices}

Invasive devices such as central venous catheters and indwelling urinary catheters increase the risk that CRE carriers will develop clinical infections with CRE. ${ }^{109,110}$ Invasive devices may facilitate the progression from carriage to infection by providing a portal of entry. Likewise, caring for these devices without adequate hand hygiene and aseptic technique creates opportunities for introducing CRE from contaminated areas to clean areas on the patient. ${ }^{110}$ The CDC classifies limiting the use of invasive devices as a core measure for controlling CRE. ${ }^{144}$ Clearly there is room for reducing the use of these devices. Studies conducted in ICUs found, for example, that $32 \%$ of urinary catheter-days were unnecessary ${ }^{166}$ and that $28 \%$ of patients with central venous catheters had no indication for their use. ${ }^{167}$

\section{Interventions to prevent the development of carbapenem resistance}

\section{Antimicrobial stewardship}

Many studies have demonstrated that recent exposure to antibiotics is a risk factor for CRE carriage or infection. ${ }^{101,102,168,169}$ Therefore, efforts to optimize antibiotic use and limit unnecessary use (antibiotic stewardship) are considered a core measure to control CRE. ${ }^{144}$ Several hospitals have restricted carbapenem use as part of a bundle of interventions that successfully controlled CRE outbreaks. ${ }^{155,170,171}$ However, in a single (non-bundled) intervention in an Iranian ICU, a 60\% decrease in carbapenem use with no concomitant change in total antibiotic use failed to increase the proportion of Enterobacteriaceae isolates susceptible to imipenem. ${ }^{172}$ Because carbapenem resistance among Enterobacteriaceae can develop following exposure to nearly any class of antibiotics, reducing overall antibiotic use is more important than restricting carbapenems. ${ }^{94,140}$

\section{Treatment of CRE infections}

Currently there is no licensed antibiotic with proven effectiveness against CRE. No randomized controlled trials have compared the available options to determine which is best for treating CRE infections at different sites. What is known about different agents' effectiveness in humans is based on syntheses of case series. ${ }^{20,173-175}$ Weaknesses of these case series-even when combined-that limit the conclusions that can be drawn from them include the frequent adjustments of drugs and dosages during treatment, confounding by indication (i.e., severely ill patients receive different regimens than less sick patients, making comparisons difficult), and the small number of patients studied.

Clinical decisions about treatment are based on laboratory tests that classify a specimen as susceptible, intermediate, or resistant to a given antibiotic. However, as mentioned earlier, treatment with an antibiotic in the susceptible category does not predict clinical success; several studies found no difference in mortality between patients who did or did not receive treatment with a drug with in vitro activity against CRE. ${ }^{113,116,118,176}$

\section{Colistin}

Colistin (polymixin E) has been in use since the late 1950s. Because it can cause nephrotoxicity and neurotoxicity, its use waned in the 1970s and was replaced by less toxic aminoglycosides. Beginning in the early 2000s, there was a revival of interest in colistin for the treatment of multidrug-resistant organisms; however, several problems complicate its use for the treatment of CRE infections. First, determining in vitro susceptibility is not straightforward, as isolates may be falsely labeled "susceptible," and there is disagreement as to what should be considered the susceptibility breakpoint. ${ }^{177}$ Second, the optimal dosage of colistin is unknown. Because the drug was developed in the era before rigorous drug development trials, data on pharmacokinetics and pharmacodynamics, which form the basis of prescribing recommendations are lacking. ${ }^{177}$ Third, nephrotoxicity remains a common, albeit reversible, adverse event. In recent studies, estimates of the proportion of patients who develop nephrotoxicity during colistin therapy range from 33\% 
to $54 \%$; higher doses were associated with greater toxicity. ${ }^{178-182}$ The clinical effectiveness of colistin is poor; in a review of 72 patients treated with colistin only, treatment failed in $47 \%$ of them. When colistin was combined with tigecycline or an aminoglycoside, treatment failed in 17 of 53 patients (32\%). The combination of colistin and a carbapenem was most successful, with only 1 out of 17 patients failing treatment. ${ }^{20}$

\section{Tigecycline}

Tigecycline was approved by the U.S. Food and Drug Administration in 2005. Because tigecycline poorly penetrates certain anatomical sites, including serum, urine, and epithelial lining fluid, ${ }^{100}$ it is not approved for the treatment of hospital-acquired pneumonia, bacteremia, or urinary tract infections. In 11 studies in which a total of 26 patients with CRE infections were treated with tigecycline, treatment failed in $29 \%$ of those who received tigecycline alone and in $37 \%$ of those who received tigecycline plus another antibiotic. ${ }^{174}$ In 2013, the FDA issued a black box warning noting the increased risk of death with tigecycline $(2.5 \%)$ compared with other antibiotics $(1.8 \%)$; the deaths resulted from worsening infections, complications of infections (i.e., treatment failure), or underlying medical conditions. The FDA advised limiting tigecycline use to situations in which alternative treatments are not suitable. ${ }^{183}$ It is prudent to limit its use to treatment of skin and skin structure infections and complicated intra-abdominal infections, two anatomic sites where tigecycline penetrates adequately.

\section{Aminoglycosides}

Among this class of antibiotics, amikacin, gentamicin, and tobramycin are commonly used. A fourth drug with increased resilience to carbapenemases, plazomicin, is still in development. ${ }^{184}$ First introduced in 1944, aminoglycosides fell out of favor in the 1980s, as new drugs, such as $\beta$-lactams combined with $\beta$-lactamase inhibitors and broadspectrum cephalosporins, became available. Side effects, primarily nephrotoxicity, contributed to aminoglycosides' decline, but lack of treatment options for multidrug-resistant Gram-negative organisms has led to renewed use of this drug class. ${ }^{185,186}$ In vitro susceptibility of CRE isolates to aminoglycosides varies with the resistance mechanism and the specific isolate. In a study of 82 CRE isolates, 1/12 KPC producers, 5/19 OXA-48 producers, and 17/17
NDM producers were resistant to gentamicin. ${ }^{187}$ In studies of patients with KPC-producing $K$. pneumoniae infections, aminoglycoside treatment failed in $1 / 10$ cases of monotherapy and in $8 / 32$ cases of combination therapy. ${ }^{20}$ Among patients with CRE bacteriuria, aminoglycoside monotherapy achieved a microbiological cure in $88 \%$ of patients, significantly more than colistin (64\%), tigecycline $(43 \%)$, or no treatment $(36 \%){ }^{188}$

\section{Carbapenems}

Paradoxically, carbapenems have a role in the treatment of CRE infections. In 2011, the EUCAST lowered its Enterobacteriaceae resistance breakpoint for imipenem/meropenem from $>8 \mathrm{mg} / \mathrm{L}$ to $>4 \mathrm{mg} / \mathrm{L}$. It appears that isolates in the zone between the old and new breakpoint may respond to carbapenem therapy. In a review of 44 CREinfected patients from 10 studies who received carbapenem monotherapy, treatment succeeded in $69 \%$ of patients whose isolates had an MIC $\leq 4$ $\mathrm{mg} / \mathrm{L}, 60 \%$ of patients with an MIC of $8 \mathrm{mg} / \mathrm{L}$, and $29 \%$ with an MIC $>8 .{ }^{189}$ At least two researchers have concluded that carbapenems are a reasonable option for treating CRE when the MIC is $\leq 4$ or even $\leq 8 \mathrm{mg} / \mathrm{L}$, when a second antibiotic is added, and when the carbapenem is given by a high-dose prolonged infusion regimen to achieve high serum concentrations. ${ }^{20,189}$ One animal study has suggested that double-carbapenem therapy may be an effective strategy for treating CRE infections; in this therapy the drug more easily hydrolyzed by carbapenemases (e.g., ertapenem) saturates the enzymes (the carbapenemases), leaving higher concentrations of less hydrolysable drug (e.g., doripenem) available to treat the infection. ${ }^{190}$

\section{Monotherapy versus combination therapy}

Possible advantages of combination therapy include (1) synergistic effects observed in vitro that lead to better clinical outcomes and (2) secondary resistance may emerge to a drug given alone. ${ }^{191,192} \mathrm{Ev}$ idence regarding the first point is inconclusive. In a review of 20 observational studies, Falagas et al. reported that the majority found no significant differences in mortality or treatment failure between patients who received monotherapy and those who received combination therapy; however, in three studies that included only critically ill patients with CRE bacteremia, mortality was significantly lower in patients given combination therapy. ${ }^{175}$ In the largest 
Table 2. Antibiotics in development with activity against CRE

\begin{tabular}{|c|c|c|c|c|c|c|c|}
\hline Drug & Class & Description & $\begin{array}{c}\text { Activity against } \\
\text { carbapenemase } \\
\text { producers }\end{array}$ & $\begin{array}{c}\text { Phase of } \\
\text { development }\end{array}$ & $\begin{array}{l}\text { Do trials include } \\
\text { a specific aim of } \\
\text { evaluating } \\
\text { efficacy against } \\
\text { CRE infections? }\end{array}$ & $\begin{array}{l}\text { Infections } \\
\text { targeted in } \\
\text { clinical } \\
\text { trials }\end{array}$ & Reference \\
\hline \multicolumn{8}{|c|}{ Beta-lactamase inhibitors that inhibit carbapenemases } \\
\hline $\begin{array}{c}\text { Ceftazidime- } \\
\text { avibactam }\end{array}$ & $\begin{array}{l}\text { Cephalosporin }+ \\
\text { beta-lactamase } \\
\text { inhibitor }\end{array}$ & $\begin{array}{l}\text { Avibactam: } \\
\text { non-beta-lactam } \\
\text { agent with } \\
\text { excellent } \\
\text { inhibition of class } \\
\text { A and class C } \\
\text { beta-lactamases, } \\
\text { including KPC. }\end{array}$ & $\begin{array}{l}\text { Active against } \\
\text { KPC and } \\
\text { OXA- } 48 \text { but } \\
\text { not MBLs. }\end{array}$ & III & 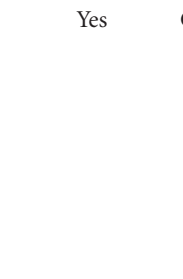 & $\begin{array}{l}\text { Complicated } \\
\text { intra-abdominal } \\
\text { infection; } \\
\text { complicated urinary } \\
\text { tract infection; } \\
\text { nosocomial } \\
\text { pneumonia; } \\
\text { targeted study of } \\
\text { resistant organisms. }\end{array}$ & 197 \\
\hline $\begin{array}{l}\text { Ceftaroline- } \\
\text { avibactam }\end{array}$ & $\begin{array}{l}\text { Cephalosporin }+ \\
\text { beta-lactamase } \\
\text { inhibitor }\end{array}$ & & $\begin{array}{l}\text { Active against } \\
\text { KPC and } \\
\text { OXA- } 48 \text { but } \\
\text { not MBLs. }\end{array}$ & II & No & $\begin{array}{l}\text { Complicated urinary } \\
\text { tract infection. }\end{array}$ & 197 \\
\hline $\begin{array}{l}\text { Aztreonam- } \\
\text { avibactam }\end{array}$ & $\begin{array}{l}\text { Monobactam }+ \\
\text { beta-lactamase } \\
\text { inhibitor }\end{array}$ & & $\begin{array}{l}\text { Active against } \\
\text { KPC, OXA-48 } \\
\text { and MBLs. }\end{array}$ & I & No & & 197 \\
\hline $\begin{array}{l}\text { Imipenem- } \\
\text { MK7655 }\end{array}$ & $\begin{array}{l}\text { Carbapenem }+ \\
\text { beta-lactamase } \\
\text { inhibitor }\end{array}$ & $\begin{array}{l}\text { MK-7655: } \\
\text { non-beta-lactam } \\
\text { agent with } \\
\text { excellent } \\
\text { inhibition of class } \\
\text { A and class C } \\
\text { beta-lactamases, } \\
\text { including KPC. }\end{array}$ & $\begin{array}{l}\text { Active against } \\
\text { KPC; weakly } \\
\text { active against } \\
\text { OXA-48; not } \\
\text { active against } \\
\text { MBLs. }\end{array}$ & II & Yes & $\begin{array}{l}\text { Complicated urinary } \\
\text { tract infection; } \\
\text { complicated } \\
\text { intra-abdominal } \\
\text { infection. }\end{array}$ & 198 \\
\hline $\begin{array}{l}\text { Carbavance } \\
\text { (RPX2014/ } \\
\text { RPX7009) }\end{array}$ & $\begin{array}{l}\text { Carbapenem }+ \\
\text { beta-lactamase } \\
\text { inhibitor }\end{array}$ & $\begin{array}{l}\text { RPX-7009: boronic } \\
\text { acid-containing } \\
\text { inhibitor of class A } \\
\text { beta-lactamases, } \\
\text { including KPC. }\end{array}$ & $\begin{array}{l}\text { Active against } \\
\text { KPC, not } \\
\text { active against } \\
\text { OXA- } 48 \text { or } \\
\text { MBLs. }\end{array}$ & III & Yes & $\begin{array}{l}\text { Complicated urinary } \\
\text { tract infection; } \\
\text { nosocomial } \\
\text { pneumonia; } \\
\text { bacteremia; targeted } \\
\text { study of resistant } \\
\text { organisms. }\end{array}$ & 199 \\
\hline \multicolumn{8}{|l|}{ Aminoglycosides } \\
\hline Plazomicin & Aminoglycoside & $\begin{array}{l}\text { Semi-synthetic } \\
\text { aminoglycoside, } \\
\text { retains activity } \\
\text { against isolates } \\
\text { with transferable } \\
\text { aminoglycoside- } \\
\text { modifying } \\
\text { enzymes, but not } \\
\text { against those with } \\
\text { ribosomal methyl- } \\
\text { transferases. }\end{array}$ & $\begin{array}{l}\text { Active against } \\
\text { most } \\
\text { carbapenemase- } \\
\text { producing } \\
\text { Enterobacteri- } \\
\text { aceae, with the } \\
\text { exception of } \\
\text { many NDM-1 } \\
\text { producers. }\end{array}$ & III & Yes & $\begin{array}{l}\text { Complicated urinary } \\
\text { tract infection; CRE } \\
\text { bacteremia; CRE } \\
\text { nosocomial } \\
\text { pneumonia. }\end{array}$ & 187 \\
\hline \multicolumn{8}{|c|}{ Tetraycline derivatives } \\
\hline Eravacycline & Tetracycline & $\begin{array}{l}\text { Fluorocycline active } \\
\text { against the main } \\
\text { acquired } \\
\text { tetracycline- } \\
\text { specific resistance } \\
\text { mechanisms } \\
\text { (efflux pumps and } \\
\text { ribosomal } \\
\text { protection). }\end{array}$ & $\begin{array}{l}\text { Active against } \\
\text { KPC; few } \\
\text { isolates with } \\
\text { other car- } \\
\text { bapenemases } \\
\text { have been } \\
\text { tested. }\end{array}$ & III & No & $\begin{array}{l}\text { Complicated urinary } \\
\text { tract infection; } \\
\text { complicated } \\
\text { intra-abdominal } \\
\text { infection. }\end{array}$ & 200 \\
\hline
\end{tabular}

${ }^{a}$ Descriptions of clinical trials available at http://clinicaltrials.gov. 
of these three studies, which included 125 patients, 30 -day mortality was $54 \%$ for monotherapy and $34 \%$ for combination therapy; 30 -day mortality was lowest $(25 \%)$ when combination therapy included a carbapenem. ${ }^{193}$

To date, only one study comparing monotherapy to combination therapy for CRE has examined resistance as an outcome. ${ }^{194}$ That study compared 12 patients whose CRKP infections were treated with polymixin B (a drug closely related to colistin) alone to four patients treated with polymixin B plus tigecycline. Samples taken after treatment showed rising MICs to polymixin B in three of the patients given monotherapy and in none of the patients given both drugs.

Currently, there is no convincing evidence that combination therapy is superior or inferior to single therapy, and treatment decisions should be made on clinical grounds according to the individual patient and strain characteristics. Two large trials, one funded by the U.S. National Institutes of Health and one funded by the European Commission, are now being conducted to examine this question. ${ }^{195,196}$

\section{Drugs in development}

Table 2 outlines the antibiotics in development that are active against CRE. For an in-depth review, see Refs. 20 and 184.

\section{Conclusions}

Carbapenem resistance in Enterobacteriaceae, primarily due to the spread of the four carbapenemases KPC, NDM, OXA-48, and VIM, is an emerging clinical and public health problem that threatens the effectiveness of the last currently available antibiotic group highly active against multidrug-resistant Enterobacteriaceae. The spread of these extremely drug-resistant organisms may limit the ability of healthcare institutions to provide complex medical treatment in a safe manner. The epidemiology of CRE varies between countries; however, it is evident that without stringent infection control measures these organisms may rapidly become endemic. Treatment options for CRE are limited and of uncertain benefit. CRE, due to their rapid spread, poor treatment options, and associated severe outcomes, challenge our healthcare systems and highlight weaknesses in sanitation and hygiene. Fortunately, the problem of CRE has attracted the attention of the pharmaceutical industry and regulatory agencies, and new agents are currently in advanced development. Until these new drugs are available, understanding the local epidemiology and designing and implementing control measures that are tailored to the local modes of spread are of highest priority.

\section{Acknowledgments}

This work was supported by the European Commission FP7 AIDA project (Preserving old antibiotics for the future: assessment of clinical efficacy by a pharmacokinetic/pharmacodynamic approach to optimize effectiveness and reduce resistance for off-patent antibiotics), Grant number 278348.

\section{Conflicts of interest}

During the last five years, Yehuda Carmeli, his laboratory, and studies that he has conducted, received grants, honoraria, travel support, consulting fees, and other forms of financial support from the following companies: Achaogen Inc, Allecra Therapeutics, AstraZeneca, Basilea Pharmaceutica LTD, Biomerieux SA, DaVolterra, Durata Therapeutics, Inc, Intercell AG, Merck \& Co. Inc, PPD, Proteologics, Rempex Pharmaceuticals, Rib-X Pharmaceuticals, and Syntezza Bioscience LTD.

\section{References}

1. Naas, T., L. Vandel, W. Sougakoff, et al. 1994. Cloning and sequence analysis of the gene for a carbapenem-hydrolyzing class A beta-lactamase, Sme-1, from Serratia marcescens S6. Antimicrob. Agents Chemother. 38: 1262-1270.

2. Queenan, A.M., C. Torres-Viera, H.S. Gold, et al. 2000. SME-type carbapenem-hydrolyzing class A betalactamases from geographically diverse Serratia marcescens strains. Antimicrob. Agent Chemother. 44: 3035-3039.

3. Watanabe, M., S. Iyobe, M. Inoue \& S. Mitsuhashi. 1991. Transferable imipenem resistance in Pseudomonas aeruginosa. Antimicrob. Agent Chemother. 35: 147-151.

4. Ito, H., Y. Arakawa, S. Ohsuka, et al. 1995. Plasmidmediated dissemination of the metallo-beta-lactamase gene blaIMP among clinically isolated strains of Serratia marcescens. Antimicrob. Agents Chemother. 39: 824829.

5. Senda, K., Y. Arakawa, S. Ichiyama, et al. 1996. PCR detection of metallo-beta-lactamase gene (blaIMP) in Gramnegative rods resistant to broad-spectrum beta-lactams. J. Clin. Microbiol. 34: 2909-2913.

6. Yigit, H., A.M. Queenan, G.J. Anderson, et al. 2001. Novel carbapenem-hydrolyzing beta-lactamase, KPC-1, from a carbapenem-resistant strain of Klebsiella pneumoniae. Antimicrob. Agents Chemother. 45: 1151-1161. 
7. Woodford, N., P.M. Tierno, Jr., K. Young, et al. 2004. Outbreak of Klebsiella pneumoniae producing a new carbapenem-hydrolyzing class A beta-lactamase, KPC-3, in a New York Medical Center. Antimicrob. Agents Chemother. 48: 4793-4799.

8. Bratu, S., M. Mooty, S. Nichani, et al. 2005. Emergence of KPC-possessing Klebsiella pneumoniae in Brooklyn, New York: epidemiology and recommendations for detection. Antimicrob. Agents Chemother. 49: 3018-3020.

9. Bratu, S., P. Tolaney, U. Karumudi, et al. 2005. Carbapenemase-producing Klebsiella pneumoniae in Brooklyn, NY: molecular epidemiology and in vitro activity of polymyxin B and other agents. J. Antimicrob. Chemother. 56: $128-132$.

10. Hidron, A.I., J.R. Edwards, J. Patel, et al. 2008. NHSN annual update: antimicrobial-resistant pathogens associated with healthcare-associated infections: annual summary of data reported to the National Healthcare Safety Network at the Centers for Disease Control and Prevention, 20062007. Infect. Control Hospital Epidemiol. 29: 996-1011.

11. Schwaber, M.J., B. Lev, A. Israeli, et al. 2011. Containment of a country-wide outbreak of carbapenem-resistant Klebsiella pneumoniae in Israeli hospitals via a nationally implemented intervention. Clin. Infect. Dis. 52: 848-855.

12. Leavitt, A., S. Navon-Venezia, I. Chmelnitsky, et al. 2007. Emergence of KPC-2 and KPC-3 in carbapenem-resistant Klebsiella pneumoniae strains in an Israeli hospital. Antimicrob. Agents Chemother. 51: 3026-3029.

13. Pournaras, S., E. Protonotariou, E. Voulgari, et al. 2009. Clonal spread of KPC-2 carbapenemase-producing Klebsiella pneumoniae strains in Greece. J. Antimicrob. Chemother. 64: 348-352.

14. Maltezou, H.C., P. Giakkoupi, A. Maragos, et al. 2009. Outbreak of infections due to KPC-2-producing Klebsiella pneumoniae in a hospital in Crete (Greece). J. Infect. 58: 213-219.

15. Mezzatesta, M.L., F. Gona, C. Caio, et al. 2011. Outbreak of KPC-3-producing, and colistin-resistant, Klebsiella pneumoniae infections in two Sicilian hospitals. Clin. Microbiol. Infect. 17: 1444-1447.

16. Miriagou, V., E. Tzelepi, D. Gianneli \& L.S. Tzouvelekis. 2003. Escherichia coli with a self-transferable, multiresistant plasmid coding for metallo-beta-lactamase VIM-1. Antimicrob. Agents Chemother. 47: 395-397.

17. Vatopoulos, A. 2008. High rates of metallo-beta-lactamaseproducing Klebsiella pneumoniae in Greece-a review of the current evidence. Euro Surv. 13: pii 8023.

18. Luzzaro, F., J.D. Docquier, C. Colinon, et al. 2004. Emergence in Klebsiella pneumoniae and Enterobacter cloacae clinical isolates of the VIM-4 metallo-beta-lactamase encoded by a conjugative plasmid. Antimicrob. Agents Chemother. 48: 648-650.

19. Tortola, M.T., S. Lavilla, E. Miro, et al. 2005. First detection of a carbapenem-hydrolyzing metalloenzyme in two Enterobacteriaceae isolates in Spain. Antimicrob. Agents Chemother. 49: 3492-3494.

20. Tzouvelekis, L.S., A. Markogiannakis, M. Psichogiou, et al. 2012. Carbapenemases in Klebsiella pneumoniae and other
Enterobacteriaceae: an evolving crisis of global dimensions. Clin. Microbiol. Rev. 25: 682-707.

21. Alba, J., Y. Ishii, K. Thomson, et al. 2005. Kinetics study of KPC-3, a plasmid-encoded class A carbapenemhydrolyzing beta-lactamase. Antimicrob. Agents Chemother. 49: $4760-4762$.

22. Cuzon, G., T. Naas, H. Truong, et al. 2010. Worldwide diversity of Klebsiella pneumoniae that produce beta-lactamase blaKPC-2 gene. Emerg. Infect. Dis. 16: 1349-1356.

23. Warburg, G., C. Hidalgo-Grass, S.R. Partridge, et al. 2012. A carbapenem-resistant Klebsiella pneumoniae epidemic clone in Jerusalem: sequence type 512 carrying a plasmid encoding aac $\left(6^{\prime}\right)$-Ib. J. Antimicrob. Chemother. 67: 898901.

24. Richter, S.N., I. Frasson, E. Franchin, et al. 2012. KPCmediated resistance in Klebsiella pneumoniae in two hospitals in Padua, Italy, June 2009-December 2011: massive spreading of a KPC-3-encoding plasmid and involvement of non-intensive care units. Gut Pathogens 4: 7.

25. Baraniak, A., A. Grabowska, R. Izdebski, et al. 2011. Molecular characteristics of KPC-producing Enterobacteriaceae at the early stage of their dissemination in Poland, 20082009. Antimicrob. Agents Chemother. 55: 5493-5499.

26. Samuelsen, O., U. Naseer, S. Tofteland, et al. 2009. Emergence of clonally related Klebsiella pneumoniae isolates of sequence type 258 producing plasmid-mediated KPC carbapenemase in Norway and Sweden. J. Antimicrob. Chemother. 63: 654-658.

27. Qi, Y., Z. Wei, S. Ji, et al. 2011. ST11, the dominant clone of KPC-producing Klebsiella pneumoniae in China. J. Antimicrob. Chemother. 66: 307-312.

28. Chmelnitsky, I., M. Shklyar, O. Hermesh, et al. 2013. Unique genes identified in the epidemic extremely drugresistant KPC-producing Klebsiella pneumoniae sequence type 258. J. Antimicrob. Chemother. 68: 74-83.

29. Adler, A., E. Khabra, I. Chmelnitsky, et al. 2014. Development and validation of a multiplex PCR assay for identification of the epidemic ST-258/512 KPC-producing Klebsiella pneumoniae clone. Diag. Microbiol. Infect. Dis. 78: 12-15.

30. Goren, M.G., S. Navon-Venezia, I. Chmelnitsky \& Y. Carmeli. 2010. Carbapenem-resistant KPC-2-producing Escherichia coli in a Tel Aviv Medical Center, 2005 to 2008. Antimicrob. Agents Chemother. 54: 2687-2691.

31. Marchaim, D., S. Navon-Venezia, M.J. Schwaber \& Y. Carmeli. 2008. Isolation of imipenem-resistant Enterobacter species: emergence of KPC-2 carbapenemase, molecular characterization, epidemiology, and outcomes. Antimicrob. Agents Chemother. 52: 1413-1418.

32. Kim, Y.A., Z.A. Qureshi, J.M. Adams-Haduch, et al. 2012. Features of infections due to Klebsiella pneumoniae carbapenemase-producing Escherichia coli: emergence of sequence type 131. Clin. Infect. Dis. 55: 224-231.

33. Naas, T., G. Cuzon, O. Gaillot, et al. 2011. When carbapenem-hydrolyzing beta-lactamase Kpc meets Escherichia coli ST131 in France. Antimicrob. Agents Chemother. 55: 4933-4934.

34. Morris, D., F. Boyle, C. Ludden, et al. 2011. Production of KPC-2 carbapenemase by an Escherichia coli clinical isolate 
belonging to the international ST131 clone. Antimicrob. Agents Chemother. 55: 4935-4936.

35. Geffen, Y., A. Adler, S. Paikin, et al. 2013. Detection of the plasmid-mediated KPC-2 carbapenem-hydrolysing enzyme in three unusual species of the Enterobacteriaceae family in Israel. J. Antimicrob. Chemother. 68: 719-720.

36. Cuzon, G., T. Naas, M.V. Villegas, et al. 2011. Wide dissemination of Pseudomonas aeruginosa producing betalactamase blaKPC-2 gene in Colombia. Antimicrob. Agents Chemother. 55: 5350-5353.

37. Naas, T., G. Cuzon, H.V. Truong \& P. Nordmann. 2012. Role of ISKpn7 and deletions in blaKPC gene expression. Antimicrob. Agents Chemother. 56: 4753-4759.

38. Kitchel, B., J.K. Rasheed, A. Endimiani, et al. 2010. Genetic factors associated with elevated carbapenem resistance in KPC-producing Klebsiella pneumoniae. Antimicrob. Agents Chemother. 54: 4201-4207.

39. Cuzon, G., T. Naas \& P. Nordmann. 2011. Functional characterization of Tn4401, a Tn3-based transposon involved in blaKPC gene mobilization. Antimicrob. Agents Chemother. 55: 5370-5373.

40. Andrade, L.N., T. Curiao, J.C. Ferreira, et al. 2011. Dissemination of blaKPC-2 by the spread of Klebsiella pneumoniae clonal complex 258 clones (ST258, ST11, ST437) and plasmids (IncFII, IncN, IncL/M) among Enterobacteriaceae species in Brazil. Antimicrob. Agents Chemother. 55: 3579-3583.

41. Leavitt, A., I. Chmelnitsky, I. Ofek, et al. 2010. Plasmid pKpQIL encoding KPC-3 and TEM-1 confers carbapenem resistance in an extremely drug-resistant epidemic Klebsiella pneumoniae strain. J. Antimicrob. Chemother. 65: 243248.

42. Chen, L., K.D. Chavda, R.G. Melano, et al. 2014. Comparative genomic analysis of KPC-encoding $\mathrm{PKpQIL-like}$ plasmids and their distribution in New Jersey and New York Hospitals. Antimicrob. Agents Chemother. 58: 2871-2877.

43. Garcia-Fernandez, A., L. Villa, C. Carta, et al. 2012. Klebsiella pneumoniae ST258 producing KPC-3 identified in italy carries novel plasmids and OmpK36/OmpK35 porin variants. Antimicrob. Agents Chemother. 56: 2143-2145.

44. Adler, A. \& Y. Carmeli. 2011. Dissemination of the Klebsiella pneumoniae carbapenemase in the health care settings: tracking the trails of an elusive offender. MBio 2: pii e00280-11.

45. Goren, M.G., Y. Carmeli, M.J. Schwaber, et al. 2010. Transfer of carbapenem-resistant plasmid from Klebsiella pneumoniae ST258 to Escherichia coli in patient. Emerg. Infect. Dis. 16: 1014-1017.

46. Walther-Rasmussen, J. \& N. Hoiby. 2006. OXA-type carbapenemases. J. Antimicrob. Chemother. 57: 373-383.

47. Kasap, M., S. Torol, F. Kolayli, et al. 2013. OXA-162, a novel variant of OXA-48 displays extended hydrolytic activity towards imipenem, meropenem and doripenem. J. Enzyme Inhib. Med. Chem. 28: 990-996.

48. Poirel, L., M. Castanheira, A. Carrer, et al. 2011. OXA-163, an OXA-48-related class D beta-lactamase with extended activity toward expanded-spectrum cephalosporins. Antimicrob. Agents Chemother. 55: 2546-2551.
49. Potron, A., P. Nordmann \& L. Poirel. 2013. Characterization of OXA-204, a carbapenem-hydrolyzing class D betalactamase from Klebsiella pneumoniae. Antimicrob. Agents Chemother. 57: 633-636.

50. Zong, Z. 2012. Discovery of bla(OXA-199), a chromosomebased bla(OXA-48)-like variant, in Shewanella xiamenensis. PloS One 7: e48280.

51. Potron, A., E. Rondinaud, L. Poirel, et al. 2013. Genetic and biochemical characterisation of OXA-232, a carbapenemhydrolysing class D beta-lactamase from Enterobacteriaceae. Int. J. Antimicrob. Agents 41: 325-329.

52. Oteo, J., J.M. Hernandez, M. Espasa, et al. 2013. Emergence of OXA-48-producing Klebsiella pneumoniae and the novel carbapenemases OXA-244 and OXA-245 in Spain. J. Antimicrob. Chemother. 68: 317-321.

53. Potron, A., P. Nordmann, E. Lafeuille, et al. 2011. Characterization of OXA-181, a carbapenem-hydrolyzing class D beta-lactamase from Klebsiella pneumoniae. Antimicrob. Agents Chemother. 55: 4896-4899.

54. Lascols, C., G. Peirano, M. Hackel, et al. 2013. Surveillance and molecular epidemiology of Klebsiella pneumoniae isolates that produce carbapenemases: first report of OXA-48-like enzymes in North America. Antimicrob. Agents Chemother. 57: 130-136.

55. Voulgari, E., O. Zarkotou, K. Ranellou, et al. 2013. Outbreak of OXA-48 carbapenemase-producing Klebsiella pneumoniae in Greece involving an ST11 clone. J. Antimicrob. Chemother. 68: 84-88.

56. Cuzon, G., J. Ouanich, R. Gondret, et al. 2011. Outbreak of OXA-48-positive carbapenem-resistant Klebsiella pneumoniae isolates in France. Antimicrob. Agents Chemother. 55: 2420-2423.

57. Baraniak, A., R. Izdebski, J. Fiett, et al. 2013. Comparative population analysis of Klebsiella pneumoniae strains with extended-spectrum beta-lactamases colonizing patients in rehabilitation centers in four countries. Antimicrob. Agents Chemother. 57: 1992-1997.

58. Morris, D., E. McGarry, M. Cotter, et al. 2012. Detection of OXA-48 carbapenemase in the pandemic clone Escherichia coli O25b:H4-ST131 in the course of investigation of an outbreak of OXA-48-producing Klebsiella pneumoniae. Antimicrob. Agents Chemother. 56: 4030-4031.

59. Carrer, A., L. Poirel, M. Yilmaz, et al. 2010. Spread of OXA48-encoding plasmid in Turkey and beyond. Antimicrob. Agents Chemother. 54: 1369-1373.

60. Aubert, D., T. Naas, C. Heritier, et al. 2006. Functional characterization of IS1999, an IS4 family element involved in mobilization and expression of beta-lactam resistance genes. J. Bacteriol. 188: 6506-6514.

61. Poirel, L., R.A. Bonnin \& P. Nordmann. 2012. Genetic features of the widespread plasmid coding for the carbapenemase OXA-48. Antimicrob. Agents Chemother. 56: 559562.

62. Adler, A., M. Shklyar, M.J. Schwaber, et al. 2011. Introduction of OXA-48-producing Enterobacteriaceae to Israeli hospitals by medical tourism. J. Antimicrob. Chemother. 66: 2763-2766.

63. Pfeifer, Y., K. Schlatterer, E. Engelmann, et al. 2012. Emergence of OXA-48-type carbapenemase-producing 
Enterobacteriaceae in German hospitals. Antimicrob. Agents Chemother. 56: 2125-2128.

64. Dortet, L., G. Cuzon \& P. Nordmann. 2014. Dissemination of carbapenemase-producing Enterobacteriaceae in France, 2012. J. Antimicrob. Chemother. 69: 623-627.

65. Potron, A., L. Poirel \& P. Nordmann. 2011. Origin of OXA181, an emerging carbapenem-hydrolyzing oxacillinase, as a chromosomal gene in Shewanella xiamenensis. Antimicrob. Agents Chemother. 55: 4405-4407.

66. Castanheira, M., L.M. Deshpande, D. Mathai, et al. 2011. Early dissemination of NDM-1- and OXA-181-producing Enterobacteriaceae in Indian hospitals: report from the SENTRY Antimicrobial Surveillance Program, 2006-2007. Antimicrob. Agents Chemother. 55: 1274-1278.

67. Poirel, L., L. Dortet, S. Bernabeu \& P. Nordmann. 2011. Genetic features of blaNDM-1-positive Enterobacteriaceae. Antimicrob. Agents Chemother. 55: 5403-5407.

68. Kumarasamy, K.K., M.A. Toleman, T.R. Walsh, et al. 2010. Emergence of a new antibiotic resistance mechanism in India, Pakistan, and the UK: a molecular, biological, and epidemiological study. Lancet Infect. Dis. 10: 597-602.

69. Lachish, T., M. Elimelech, N. Arieli, et al. 2012. Emergence of New Delhi metallo-beta-lactamase in Jerusalem, Israel. Int. J. Antimicrob. Agents 40: 566-567.

70. Mushtaq, S., S. Irfan, J.B. Sarma, et al. 2011. Phylogenetic diversity of Escherichia coli strains producing NDMtype carbapenemases. J. Antimicrob. Chemother. 66: 20022005.

71. Nordmann, P., A.E. Boulanger \& L. Poirel. 2012. NDM-4 metallo-beta-lactamase with increased carbapenemase activity from Escherichia coli. Antimicrob. Agents Chemother. 56: $2184-2186$.

72. Hornsey, M., L. Phee \& D.W. Wareham, 2011. A novel variant, NDM-5, of the New Delhi metallo-beta-lactamase in a multidrug-resistant Escherichia coliST648 isolate recovered from a patient in the United Kingdom. Antimicrob. Agents Chemother. 55: 5952-5954.

73. Rogers, B.A., H.E. Sidjabat, A. Silvey, et al. 2013. Treatment options for New Delhi metallo-beta-lactamase-harboring Enterobacteriaceae. Microb. Drug Resist. 19: 100-103.

74. Cuzon, G., R.A. Bonnin \& P. Nordmann. 2013. First identification of novel NDM carbapenemase, NDM-7, in Escherichia coli in France. PloS One 8: e61322.

75. Zhang, R., Y.Y. Hu, X.F. Yang, et al. 2013. Emergence of NDM-producing non-baumannii Acinetobacter spp. isolated from China. Eur. J. Clin. Microb. Infect. Dis. 33: 853860.

76. Williamson, D.A., H.E. Sidjabat, J.T. Freeman, et al. 2012. Identification and molecular characterisation of New Delhi metallo-beta-lactamase-1 (NDM-1)- and NDM-6producing Enterobacteriaceae from New Zealand hospitals. Int. J. Antimicrob. Agents 39: 529-533.

77. Tada, T., T. Miyoshi-Akiyama, R.K. Dahal, et al. 2013. NDM-8 metallo-beta-lactamase in a multidrug-resistant Escherichia coli strain isolated in Nepal. Antimicrob. Agents Chemother. 57: 2394-2396.

78. Carattoli, A. 2009. Resistance plasmid families in Enterobacteriaceae. Antimicrob. Agents Chemother. 53: 22272238 .
79. Toleman, M.A., D. Biedenbach, D.M. Bennett, et al. 2005. Italian metallo-beta-lactamases: a national problem? Report from the SENTRY Antimicrobial Surveillance Programme. J. Antimicrob. Chemother. 55: 61-70.

80. Tato, M., T.M. Coque, F. Baquero \& R. Canton. 2010. Dispersal of carbapenemase blaVIM-1 gene associated with different Tn402 variants, mercury transposons, and conjugative plasmids in Enterobacteriaceae and Pseudomonas aeruginosa. Antimicrob. Agents Chemother. 54: 320-327.

81. Lee, K., W.G. Lee, Y. Uh, et al. 2003. VIM- and IMP-type metallo-beta-lactamase-producing Pseudomonas spp. and Acinetobacter spp. in Korean hospitals. Emerg. Infect. Dis. 9: 868-871.

82. Samuelsen, O., M.A. Toleman, V. Hasseltvedt, et al. 2011. Molecular characterization of VIM-producing Klebsiella pneumoniae from Scandinavia reveals genetic relatedness with international clonal complexes encoding transferable multidrug resistance. Clin. Microbiol. Infect. 17: 1811-1816.

83. Sonnevend, A., A. Ghazawi, N. Yahfoufi, et al. 2012. VIM4 carbapenemase-producing Enterobacter cloacae in the United Arab Emirates. Clin. Microbiol. Infect. 18: E494E496.

84. Walsh, T.R. 2010. Emerging carbapenemases: a global perspective. Int. J. Antimicrob. Agents 36(Suppl 3): S8-S14.

85. Papagiannitsis, C.C., S.D. Kotsakis, E. Petinaki, et al. 2011. Characterization of metallo-beta-lactamase VIM-27, an A57S mutant of VIM-1 associated with Klebsiella pneumoniae ST147. Antimicrob. Agents Chemother. 55: 3570-3572.

86. Giakoupi, P., H. Maltezou, M. Polemis, et al. 2009. KPC-2producing Klebsiella pneumoniae infections in Greek hospitals are mainly due to a hyperepidemic clone. Euro Surv. 14: pii 19218.

87. Steinmann, J., M. Kaase, S. Gatermann, et al. 2011. Outbreak due to a Klebsiella pneumoniae strain harbouring KPC-2 and VIM-1 in a German university hospital, July 2010 to January 2011. Euro Surv. 16: pii 19944.

88. Perilli, M., C. Bottoni, A. Grimaldi, et al. 2013. Carbapenem-resistant Klebsiella pneumoniae harbouring blaKPC-3 and blaVIM-2 from central Italy. Diag. Microbiol. Infect. Dis. 75: 218-221.

89. Rojas, L.J., M.F. Mojica, V.M. Blanco, et al. 2013. Emergence of Klebsiella pneumoniae coharboring KPC and VIM carbapenemases in Colombia. Antimicrob. Agents Chemother. 57: 1101-1102.

90. Peirano, G., C. Lascols, M. Hackel, et al. 2014. Molecular epidemiology of Enterobacteriaceae that produce VIMs and IMPs from the SMART surveillance program. Diag. Microbiol. Infect. Dis. 78: 277-281

91. Hrabak, J., C.C. Papagiannitsis, V. Studentova, et al. 2013. Carbapenemase-producing Klebsiella pneumoniae in the Czech Republic in 2011. Euro Surv. 18: 20626.

92. Lupo, A., K.M. Papp-Wallace, P. Sendi, et al. 2013. Nonphenotypic tests to detect and characterize antibiotic resistance mechanisms in Enterobacteriaceae. Diag. Microb. Infect. Dis. 77: 179-194.

93. Munoz-Price, L.S., L. Poirel, R.A. Bonomo, et al. 2013. Clinical epidemiology of the global expansion of Klebsiella pneumoniae carbapenemases. Lancet Infect. Dis. 13: 785796. 
94. Gupta, N., B.M. Limbago, J.B. Patel \& A.J. Kallen. 2011. Carbapenem-resistant Enterobacteriaceae: epidemiology and prevention. Clin. Infect. Dis. 53: 60-67.

95. Nordmann, P., G. Cuzon \& T. Naas. 2009. The real threat of Klebsiella pneumoniae carbapenemase-producing bacteria. Lancet Infect. Dis. 9: 228-236.

96. Centers for Disease Control and Prevention. 2014. Tracking CRE. Available at http://www.cdc.gov/hai/ organisms/cre/TrackingCRE.html. Accessed 14 July 2014.

97. Sievert, D.M., P. Ricks, J.R. Edwards, et al. 2013. Antimicrobial-resistant pathogens associated with healthcare-associated infections: summary of data reported to the National Healthcare Safety Network at the Centers for Disease Control and Prevention, 2009-2010. Infect. Control Hospital Epidemiol. 34: 1-14.

98. Centers for Disease Control and Prevention. 2013. Vital signs: carbapenem-resistant Enterobacteriaceae. MMWR. Morbidity Mortality Weekly Rep. 62: 165-170.

99. European Centre for Disease Prevention and Control. 2013. Antimicrobial resistance surveillance in Europe 2012. Available at http://www.ecdc.europa.eu/en/activities/ surveillance/EARS-Net/Pages/index.aspx. Accessed 14 July 2014.

100. Akova, M., G.L. Daikos, L. Tzouvelekis \& Y. Carmeli. 2012. Interventional strategies and current clinical experience with carbapenemase-producing Gram-negative bacteria. Clin. Microbiol. Infect. 18: 439-448.

101. Ben-David, D., S. Masarwa, S. Navon-Venezia, et al. 2011. Carbapenem-resistant Klebsiella pneumoniae in postacute-care facilities in Israel. Infect. Control Hospital Epidemiol. 32: 845-853.

102. Swaminathan, M., S. Sharma, S. Poliansky Blash, et al. 2013. Prevalence and risk factors for acquisition of carbapenem-resistant Enterobacteriaceae in the setting of endemicity. Infect. Control Hospital Epidemiol. 34: 809817.

103. Wiener-Well, Y., B. Rudensky, A.M. Yinnon, et al. 2010. Carriage rate of carbapenem-resistant Klebsiella pneumoniae in hospitalised patients during a national outbreak. J. Hospital Infect. 74: 344-349.

104. Walsh, T.R., J. Weeks, D.M. Livermore \& M.A. Toleman. 2011. Dissemination of NDM-1 positive bacteria in the New Delhi environment and its implications for human health: an environmental point prevalence study. Lancet Infect. Dis. 11: 355-362.

105. Adler, A., S. Navon-Venezia, J. Moran-Gilad, et al. 2011. Laboratory and clinical evaluation of screening agar plates for detection of carbapenem-resistant Enterobacteriaceae from surveillance rectal swabs. J. Clin. Microbiol. 49: 22392242.

106. Feldman, N., A. Adler, N. Molshatzki, et al. 2013. Gastrointestinal colonization by KPC-producing Klebsiella pneumoniae following hospital discharge: duration of carriage and risk factors for persistent carriage. Clin. Microbiol. Infect. 19: E190-E196.

107. Schechner, V., T. Kotlovsky, J. Tarabeia, et al. 2011. Predictors of rectal carriage of carbapenem-resistant Enterobacteriaceae (CRE) among patients with known CRE carriage at their next hospital encounter. Infect. Control Hospital Epidemiol. 32: 497-503.

108. Zimmerman, F.S., M.V. Assous, T. Bdolah-Abram, et al. 2013. Duration of carriage of carbapenem-resistant Enterobacteriaceae following hospital discharge. Am. J. Infect. Control 41: 190-194.

109. Schechner, V., T. Kotlovsky, M. Kazma, et al. 2013. Asymptomatic rectal carriage of blaKPC producing carbapenemresistant Enterobacteriaceae: who is prone to become clinically infected? Clin. Microbiol. Infect. 19: 451-456.

110. Borer, A., L. Saidel-Odes, S. Eskira, et al. 2012. Risk factors for developing clinical infection with carbapenem-resistant Klebsiella pneumoniae in hospital patients initially only colonized with carbapenem-resistant K. pneumoniae. Am. J. Infect. Control 40: 421-425.

111. Schwaber, M.J., S. Klarfeld-Lidji, S. Navon-Venezia, et al. 2008. Predictors of carbapenem-resistant Klebsiella pneumoniae acquisition among hospitalized adults and effect of acquisition on mortality. Antimicrob. Agents Chemother. 52: $1028-1033$.

112. Borer, A., L. Saidel-Odes, K. Riesenberg, et al. 2009. Attributable mortality rate for carbapenem-resistant Klebsiella pneumoniae bacteremia. Infect. Control Hospital Epidemiol. 30: 972-976.

113. Patel, G., S. Huprikar, S.H. Factor, et al. 2008. Outcomes of carbapenem-resistant Klebsiella pneumoniae infection and the impact of antimicrobial and adjunctive therapies. Infect. Control Hospital Epidemiol. 29: 1099-1106.

114. Bleumin, D., M.J. Cohen, O. Moranne, et al. 2012. Carbapenem-resistant Klebsiella pneumoniae is associated with poor outcome in hemodialysis patients. J. Infect. 65: 318-325.

115. Ben-David, D., R. Kordevani, N. Keller, et al. 2012. Outcome of carbapenem resistant Klebsiella pneumoniae bloodstream infections. Clin. Microbiol. Infect. 18: 54-60.

116. Hussein, K., A. Raz-Pasteur, R. Finkelstein, et al. 2013. Impact of carbapenem resistance on the outcome of patients' hospital-acquired bacteraemia caused by Klebsiella pneumoniae. J. Hospital Infect. 83: 307-313.

117. Bhattacharya, S. 2013. Early diagnosis of resistant pathogens: how can it improve antimicrobial treatment? Virulence 4: 172-184.

118. Neuner, E.A., J.Y. Yeh, G.S. Hall, et al. 2011. Treatment and outcomes in carbapenem-resistant Klebsiella pneumoniae bloodstream infections. Diagn. Microbiol. Infect. Dis. 69: 357-362.

119. Gastmeier, P. \& R.P. Vonberg. 2014. Klebsiella spp. in endoscopy-associated infections: we may only be seeing the tip of the iceberg. Infection 42: 15-21.

120. Vergara-Lopez, S., M.C. Dominguez, M.C. Conejo, et al. 2013. Wastewater drainage system as an occult reservoir in a protracted clonal outbreak due to metallo-beta-lactamaseproducing Klebsiella oxytoca. Clin. Microbiol. Infect. 19: E490-E498.

121. Bonten, M.J. 2012. Colonization pressure: a critical parameter in the epidemiology of antibiotic-resistant bacteria. Crit. Care 16: 142.

122. Lin, M.Y., R.D. Lyles-Banks, K. Lolans, et al. 2013. The importance of long-term acute care hospitals in the regional 
epidemiology of Klebsiella pneumoniae carbapenemaseproducing Enterobacteriaceae. Clin. Infect. Dis. 57: 12461252.

123. Won, S.Y., L.S. Munoz-Price, K. Lolans, et al. 2011. Emergence and rapid regional spread of Klebsiella pneumoniae carbapenemase-producing Enterobacteriaceae. Clin. Infect. Dis. 53: 532-540.

124. Centers for Disease Control and Prevention. 2011. Carbapenem-resistant Klebsiella pneumoniae associated with a long-term-care facility — West Virginia, 2009-2011. MMWR. Morbidity Mortality Weekly Rep. 60: 1418-1420.

125. Marchaim, D., D.E. Katz \& L.S. Munoz-Price. 2013. Emergence and control of antibiotic-resistant Gram-negative bacilli in older adults. Current Transl. Geriatr. Gerontol. Rep. 2: 113-124.

126. Schwaber, M.J. \& Y. Carmeli. 2014. An ongoing national intervention to contain the spread of carbapenem-resistant Enterobacteriaceae. Clin. Infect. Dis. 58: 697-703.

127. Perez, F., A. Endimiani, A.J. Ray, et al. 2010. Carbapenemresistant Acinetobacter baumannii and Klebsiella pneumoniae across a hospital system: impact of post-acute care facilities on dissemination. J. Antimicrob. Chemother. 65: 1807-1818.

128. Marchaim, D., T. Chopra, J.M. Pogue, et al. 2011. Outbreak of colistin-resistant, carbapenem-resistant Klebsiella pneumoniae in metropolitan Detroit, Michigan. Antimicrob. Agents Chemother. 55: 593-599.

129. Nordmann, P., J.P. Couard, D. Sansot \& L. Poirel. 2012. Emergence of an autochthonous and community-acquired NDM-1-producing Klebsiella pneumoniae in Europe. Clin. Infect. Dis. 54: 150-151.

130. Arpin, C., P. Noury, D. Boraud, et al. 2012. NDM-1producing Klebsiella pneumoniae resistant to colistin in a French community patient without history of foreign travel. Antimicrob. Agents Chemother. 56: 3432-3434.

131. Glupczynski, Y., T.D. Huang, W. Bouchahrouf, et al. 2012. Rapid emergence and spread of OXA-48producing carbapenem-resistant Enterobacteriaceae isolates in Belgian hospitals. Int. J. Antimicrob. Agents 39: $168-172$.

132. Yong, D., M.A. Toleman, C.G. Giske, et al. 2009. Characterization of a new metallo-beta-lactamase gene, bla(NDM-1), and a novel erythromycin esterase gene carried on a unique genetic structure in Klebsiella pneumoniae sequence type 14 from India. Antimicrob. Agents Chemother. 53: 5046-5054.

133. Leverstein-Van Hall, M.A., J.C. Stuart, G.M. Voets, et al. 2010. Global spread of New Delhi metallo-beta-lactamase 1. Lancet Infect. Dis. 10: 830-831.

134. Poirel, L., C. Hombrouck-Alet, C. Freneaux, et al. 2010. Global spread of New Delhi metallo-beta-lactamase 1. Lancet Infect. Dis. 10: 832.

135. Khan, A.U. \& P. Nordmann. 2012. NDM-1-producing Enterobacter cloacae and Klebsiella pneumoniae from diabetic foot ulcers in India. J. Med. Microbiol. 61: 454-456.

136. Birgy, A., C. Doit, P. Mariani-Kurkdjian, et al. 2011. Early detection of colonization by VIM-1-producing Klebsiella pneumoniae and NDM-1-producing Escherichia coli in two children returning to France. J. Clin. Microbiol. 49: 30853087.
137. Isozumi, R., K. Yoshimatsu, T. Yamashiro, et al. 2012. bla(NDM-1)-positive Klebsiella pneumoniae from environment, Vietnam. Emerg. Infect. Dis. 18: 1383-1385.

138. Potron, A., L. Poirel, F. Bussy \& P. Nordmann. 2011. Occurrence of the carbapenem-hydrolyzing beta-lactamase gene blaOXA-48 in the environment in Morocco. Antimicrob. Agents Chemother. 55: 5413-5414.

139. Shahid, M., A. Malik, M. Adil, et al. 2009. Comparison of beta-lactamase genes in clinical and food bacterial isolates in India. J. Infect. Dev. Countries 3: 593-598.

140. Munoz-Price, L.S. \& J.P. Quinn. 2013. Deconstructing the infection control bundles for the containment of carbapenem-resistant Enterobacteriaceae. Curr. Opin. Infect. Dis. 26: 378-387.

141. Munoz-Price, L.S., M.K. Hayden, K. Lolans, et al. 2010. Successful control of an outbreak of Klebsiella pneumoniae carbapenemase-producing K. pneumoniae at a long-term acute care hospital. Infect. Control Hospital Epidemiol. 31: 341-347.

142. Kochar, S., T. Sheard, R. Sharma, et al. 2009. Success of an infection control program to reduce the spread of carbapenem-resistant Klebsiella pneumoniae. Infect. Control Hospital Epidemiol. 30: 447-452.

143. D’Agata, E.M., M.A. Horn, S. Ruan, et al. 2012. Efficacy of infection control interventions in reducing the spread of multidrug-resistant organisms in the hospital setting. PloS One 7: e30170.

144. Centers for Disease Control and Prevention. 2012. Guidance for control of carbapenem-resistant Enterobacteriaceae (CRE): 2012 CRE Toolkit. Available at http://www.cdc.gov/hai/organisms/cre/cre-toolkit/ Accessed 14 July 2014.

145. Carmeli, Y., M. Akova, G. Cornaglia, et al. 2010. Controlling the spread of carbapenemase-producing Gram-negatives: therapeutic approach and infection control. Clin. Microb. Infect. 16: 102-111.

146. Ben-David, D., Y. Maor, N. Keller, et al. 2010. Potential role of active surveillance in the control of a hospitalwide outbreak of carbapenem-resistant Klebsiella pneumoniae infection. Infect. Control Hospital Epidemiol. 31: 620-626.

147. Schechner, V., K. Straus-Robinson, D. Schwartz, et al. 2009. Evaluation of PCR-based testing for surveillance of KPC-producing carbapenem-resistant members of the Enterobacteriaceae family. J. Clin. Microbiol. 47: 32613265.

148. Bilavsky, E., M.J. Schwaber \& Y. Carmeli. 2010. How to stem the tide of carbapenemase-producing Enterobacteriaceae?: proactive versus reactive strategies. Curr. Opin. Infect. Dis. 23: $327-331$.

149. European Centre for Disease Prevention and Control. 2011. Risk assessment on the spread of carbapenemaseproducing Enterobacteriaceae (CPE) through patient transfer between healthcare facilities, with special emphasis on cross-border transfer. Available at http://www.ecdc.europa.eu/en/publications/technical_repo rts/arhai/Pages/arhai.aspx. Accessed 14 July 2014.

150. Kruse, E.B., U. Aurbach \& H. Wisplinghoff. 2013. Carbapenem-resistant Enterobacteriaceae: laboratory 
detection and infection control practices. Curr. Infect. Dis. Rep. 15: 549-558.

151. Calfee, D. \& S.G. Jenkins. 2008. Use of active surveillance cultures to detect asymptomatic colonization with carbapenem-resistant Klebsiella pneumoniae in intensive care unit patients. Infect. Control Hospital Epidemiol. 29: 966-968.

152. Cohen, M.J., C. Block, P.D. Levin, et al. 2011. Institutional control measures to curtail the epidemic spread of carbapenem-resistant Klebsiella pneumoniae: a 4-year perspective. Infect. Control Hospital Epidemiol. 32: 673-678.

153. Palmore, T.N. \& D.K. Henderson. 2013. Managing transmission of carbapenem-resistant Enterobacteriaceae in healthcare settings: a view from the trenches. Clin. Infect. Dis. 57: 1593-1599.

154. Siegel, J.D., E. Rhinehart, M. Jackson, et al. 2007. Management of multidrug-resistant organisms in health care settings, 2006. Am. J. Infect. Control 35: S165-S193.

155. Gregory, C.J., E. Llata, N. Stine, et al. 2010. Outbreak of carbapenem-resistant Klebsiella pneumoniae in Puerto Rico associated with a novel carbapenemase variant. Infect. Control Hospital Epidemiol. 31: 476-484.

156. Lerner, A., A. Adler, J. Abu-Hanna, et al. 2013. Environmental contamination by carbapenem-resistant Enterobacteriaceae. J. Clin. Microbiol. 51: 177-181.

157. Maltezou, H.C. 2009. Metallo-beta-lactamases in Gramnegative bacteria: introducing the era of pan-resistance? Int. J. Antimicrob. Agents 33: 405 e401-e407.

158. Climo, M.W., D.S. Yokoe, D.K. Warren, et al. 2013. Effect of daily chlorhexidine bathing on hospital-acquired infection. New England J. Med. 368: 533-542.

159. Munoz-Price, L.S., C. De La Cuesta, S. Adams, et al. 2010. Successful eradication of a monoclonal strain of Klebsiella pneumoniae during a K. pneumoniae carbapenemaseproducing K. pneumoniae outbreak in a surgical intensive care unit in Miami, Florida. Infect. Control Hospital Epidemiol. 31: 1074-1077.

160. Naparstek, L., Y. Carmeli, I. Chmelnitsky, et al. 2012. Reduced susceptibility to chlorhexidine among extremelydrug-resistant strains of Klebsiella pneumoniae. J. Hospital Infect. 81: 15-19.

161. Saidel-Odes, L., H. Polachek, N. Peled, et al. 2012. A randomized, double-blind, placebo-controlled trial of selective digestive decontamination using oral gentamicin and oral polymyxin $\mathrm{E}$ for eradication of carbapenem-resistant Klebsiella pneumoniae carriage. Infect. Control Hospital Epidemiol. 33: 14-19.

162. Oren, I., H. Sprecher, R. Finkelstein, et al. 2013. Eradication of carbapenem-resistant Enterobacteriaceae gastrointestinal colonization with nonabsorbable oral antibiotic treatment: a prospective controlled trial. Am. J. Infect. Control 41: $1167-1172$.

163. Lubbert, C., S. Faucheux, D. Becker-Rux, et al. 2013. Rapid emergence of secondary resistance to gentamicin and colistin following selective digestive decontamination in patients with KPC-2-producing Klebsiella pneumoniae: a single-centre experience. Int. J. Antimicrob. Agents 42: 565-570.
164. Wittekamp, B.H. \& M.J. Bonten. 2012. Antibiotic prophylaxis in the era of multidrug-resistant bacteria. Expert Opin. Invest. Drugs 21: 767-772.

165. van der Meer, J.W. \& C.M. Vandenbroucke-Grauls. 2013. Resistance to selective decontamination: the jury is still out. Lancet Infect. Dis. 13: 282-283.

166. Elpern, E.H., K. Killeen, A. Ketchem, et al. 2009. Reducing use of indwelling urinary catheters and associated urinary tract infections. Am. J. Crit. Care 18: 535-541.

167. Cload, B., A.G. Day \& R. Ilan. 2010. Evaluation of unnecessary central venous catheters in critically ill patients: a prospective observational study. Can. J. Anaesthesia 57: 830-835.

168. Marchaim, D., T. Chopra, A. Bhargava, et al. 2012. Recent exposure to antimicrobials and carbapenem-resistant Enterobacteriaceae: the role of antimicrobial stewardship. Infect. Control Hospital Epidemiol. 33: 817-830.

169. Chitnis, A.S., P.S. Caruthers, A.K. Rao, et al. 2012. Outbreak of carbapenem-resistant Enterobacteriaceae at a long-term acute care hospital: sustained reductions in transmission through active surveillance and targeted interventions. Infect. Control Hospital Epidemiol.: 33: 984-992.

170. Borer, A., S. Eskira, R. Nativ, et al. 2011. A multifaceted intervention strategy for eradication of a hospital-wide outbreak caused by carbapenem-resistant Klebsiella pneumoniae in Southern Israel. Infect. Control Hospital Epidemiol. 32: 1158-1165.

171. Kassis-Chikhani, N., F. Saliba, A. Carbonne, et al. 2010. Extended measures for controlling an outbreak of VIM-1 producing imipenem-resistant Klebsiella pneumoniae in a liver transplant centre in France, 2003-2004. Euro Surv. 15: pii 19713.

172. Sistanizad, M., M. Kouchek, M. Miri, et al. 2013. Carbapenem restriction and its effect on bacterial resistance in an intensive care unit of a teaching hospital. Iranian J. Pharmaceutical Res. 12: 503-509.

173. Hirsch, E.B. \& V.H. Tam. 2010. Detection and treatment options for Klebsiella pneumoniae carbapenemases (KPCs): an emerging cause of multidrug-resistant infection. J. Antimicrob. Chemother. 65: 1119-1125.

174. Lee, G.C. \& D.S. Burgess. 2012. Treatment of Klebsiella pneumoniae carbapenemase (KPC) infections: a review of published case series and case reports. Ann. Clin. Microb. Antimicrob. 11: 32 .

175. Falagas, M.E., P. Lourida, P. Poulikakos, et al. 2014. Antibiotic treatment of infections due to carbapenem-resistant Enterobacteriaceae: systematic evaluation of the available evidence. Antimicrob. Agents Chemother. 58: 654663.

176. Nguyen, M., G.A. Eschenauer, M. Bryan, et al. 2010. Carbapenem-resistant Klebsiella pneumoniae bacteremia: factors correlated with clinical and microbiologic outcomes. Diag. Microb. Infect. Dis. 67: 180-184.

177. Li, J., R.L. Nation, J.D. Turnidge, et al. 2006. Colistin: the reemerging antibiotic for multidrug-resistant Gram-negative bacterial infections. Lancet Infect. Dis. 6: 589-601.

178. Kwon, J.A., J.E. Lee, W. Huh, et al. 2010. Predictors of acute kidney injury associated with intravenous colistin treatment. Int. J. Antimicrob. Agents 35: 473-477. 
179. Deryke, C.A., A.J. Crawford, N. Uddin \& M.R. Wallace. 2010. Colistin dosing and nephrotoxicity in a large community teaching hospital. Antimicrob. Agents Chemother. 54: 4503-4505.

180. Dalfino, L., F. Puntillo, A. Mosca, et al. 2012. High-dose, extended-interval colistin administration in critically ill patients: is this the right dosing strategy? A preliminary study. Clin. Infect. Dis. 54: 1720-1726.

181. Pogue, J.M., J. Lee, D. Marchaim, et al. 2011. Incidence of and risk factors for colistin-associated nephrotoxicity in a large academic health system. Clin. Infect. Dis. 53: 879-884.

182. Rocco, M., L. Montini, E. Alessandri, et al. 2013. Risk factors for acute kidney injury in critically ill patients receiving high intravenous doses of colistin methanesulfonate and/or other nephrotoxic antibiotics: a retrospective cohort study. Crit. Care 17: R174.

183. U.S. Food and Drug Administration. 2013. FDA Drug Safety Communication: FDA warns of increased risk of death with IV antibacterial Tygacil (tigecycline) and approves new boxed warning. Available at http://www. fda.gov/Drugs/DrugSafety/DrugSafetyPodcasts/ucm37062 6.htm. Accessed 14 July 2014.

184. Pucci, M.J. \& K. Bush. 2013. Investigational antimicrobial agents of 2013. Clin. Microb. Rev. 26: 792-821.

185. Begg, E.J. \& M.L. Barclay. 1995. Aminoglycosides-50 years on. Br. J. Clin. Pharmacol. 39: 597-603.

186. Drusano, G.L. \& A. Louie. 2011. Optimization of aminoglycoside therapy. Antimicrob. Agents Chemother. 55: 25282531.

187. Livermore, D.M., S. Mushtaq, M. Warner, et al. 2011. Activity of aminoglycosides, including ACHN-490, against carbapenem-resistant Enterobacteriaceae isolates. J. Antimicrob. Chemother. 66: 48-53.

188. Satlin, M.J., C.J. Kubin, J.S. Blumenthal, et al. 2011. Comparative effectiveness of aminoglycosides, polymyxin B, and tigecycline for clearance of carbapenem-resistant Klebsiella pneumoniae from urine. Antimicrob. Agents Chemother. 55: 5893-5899.

189. Daikos, G.L. \& A. Markogiannakis. 2011. Carbapenemaseproducing Klebsiella pneumoniae: (when) might we still consider treating with carbapenems? Clin. Microb. Infect. 17: 1135-1141.

190. Bulik, C.C. \& D.P. Nicolau. 2011. Double-carbapenem therapy for carbapenemase-producing Klebsiella pneumoniae. Antimicrob. Agents Chemother. 55: 3002-3004.
191. Tamma, P.D., S.E. Cosgrove \& L.L. Maragakis. 2012. Combination therapy for treatment of infections with Gram-negative bacteria. Clin. Microb. Rev. 25: 450470.

192. Petrosillo, N., M. Giannella, R. Lewis \& P. Viale. 2013. Treatment of carbapenem-resistant Klebsiella pneumoniae: the state of the art. Exp. Rev. Anti-infective Ther. 11: 159177.

193. Tumbarello, M., P. Viale, C. Viscoli, et al. 2012. Predictors of mortality in bloodstream infections caused by Klebsiella pneumoniae carbapenemase-producing K. pneumoniae: importance of combination therapy. Clin. Infect. Dis. 55: 943-950.

194. Lee, J., G. Patel, S. Huprikar, et al. 2009. Decreased susceptibility to polymyxin B during treatment for carbapenemresistant Klebsiella pneumoniae infection. J. Clin. Microb. 47: 1611-1612.

195. National Institutes of Health. Multicenter open-label randomized controlled trial (RCT) to compare colistin alone versus colistin plus meropenem. Available at http://clinicaltrials.gov/ct2/show/NCT01732250?term $=\%$ 22 colistin+alone+versus $\% 22 \&$ recr= Open $\&$ rank $=1$. Accessed 15 June 2014.

196. National Institutes of Health. 2014. Trial for the treatment of extensively drug-resistant Gram-negative bacilli. Available at http://clinicaltrials.gov/ct2/show/NCT01597973? term $=\% 22$ trial + for + the + treatment + of + extensively + drug -resistant\%22\&rank=1. Accessed 15 June 2014.

197. Drawz, S.M., K.M. Papp-Wallace \& R.A. Bonomo. 2014. New beta-lactamase inhibitors: a therapeutic renaissance in an MDR world. Antimicrob. Agents Chemother. 58: 18351846.

198. Livermore, D.M., M. Warner \& S. Mushtaq. 2013. Activity of MK-7655 combined with imipenem against Enterobacteriaceae and Pseudomonas aeruginosa. J. Antimicrob. Chemother. 68: 2286-2290.

199. Livermore, D.M., S. Mushtaq, M. Warner \& J.C. Zhang, 2013. Activity of biapenem (RPX2003) combined with the boronate beta-lactamase inhibitor RPX7009 against carbapenem-resistant Enterobacteriaceae. J. Antimicrob. Chemother. 68: 1825-1831.

200. Sutcliffe, J.A., W. O’Brien, C. Fyfe \& T.H. Grossman. 2013. Antibacterial activity of eravacycline (TP-434), a novel fluorocycline, against hospital and community pathogens. Antimicrob. Agents Chemother. 57: 5548-5558. 